\title{
Alternative Neutron Detection Testing Summary
}

\author{
RT Kouzes \\ JH Ely \\ LE Erikson \\ WJ Kernan \\ AT Lintereur \\ ER Siciliano \\ DC Stromswold \\ ML Woodring
}

April 8, 2010

\section{Pacific Northwest}

NATIONAL LABORATORY

Proudly Operated by Battelle Since 1965 


\title{
DISCLAIMER
}

This report was prepared as an account of work sponsored by an agency of the United States Government. Neither the United States Government nor any agency thereof, nor Battelle Memorial Institute, nor any of their employees, makes any warranty, express or implied, or assumes any legal liability or responsibility for the accuracy, completeness, or usefulness of any information, apparatus, product, or process disclosed, or represents that its use would not infringe privately owned rights. Reference herein to any specific commercial product, process, or service by trade name, trademark, manufacturer, or otherwise does not necessarily constitute or imply its endorsement, recommendation, or favoring by the United States Government or any agency thereof, or Battelle Memorial Institute. The views and opinions of authors expressed herein do not necessarily state or reflect those of the United States Government or any agency thereof.

\author{
PACIFIC NORTHWEST NATIONAL LABORATORY \\ operated by \\ BATTELLE \\ for the \\ UNITED STATES DEPARTMENT OF ENERGY \\ under Contract DE-AC05-76RL01830
}

Printed in the United States of America
Available to DOE and DOE contractors from the Office of Scientific and Technical Information,
P.O. Box 62, Oak Ridge, TN 37831-0062;
ph: (865) 576-8401
fax: $(865)$ 576-5728
email: reports@adonis.osti.gov

\begin{abstract}
Available to the public from the National Technical Information Service, U.S. Department of Commerce, 5285 Port Royal Rd., Springfield, VA 22161 ph: (800) 553-6847 fax: $(703) 605-6900$ email: orders@ntis.fedworld.gov online ordering: http://www.ntis.gov/ordering.htm
\end{abstract}

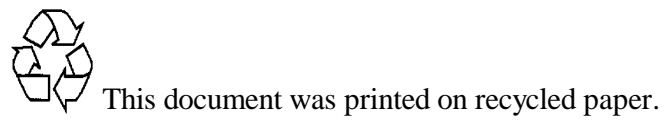


PNNL-19311

\title{
Alternative Neutron Detection Testing Summary
}

\author{
RT Kouzes \\ JH Ely \\ LE Erikson \\ WJ Kernan \\ AT Lintereur \\ ER Siciliano \\ DC Stromswold \\ ML Woodring
}

April 8, 2010

Pacific Northwest National Laboratory

Richland, Washington 99352 


\section{Executive Summary}

Radiation portal monitors used for interdiction of illicit materials at borders include highly sensitive neutron detection systems. The main reason for having neutron detection capability is to detect fission neutrons from plutonium. Most currently deployed radiation portal monitors (RPMs) use neutron detectors based upon ${ }^{3} \mathrm{He}$-filled gas proportional counters, which are the most common large area neutron detector. This type of neutron detector is used in the RPMs installed in international locations made by TSA and others, and in the Ludlum and Science Applications International Corporation RPMs deployed primarily for domestic applications. There is a declining supply of ${ }^{3} \mathrm{He}$ in the world and, thus, methods to reduce the use of this gas in RPMs with minimal changes to the current system designs and sensitivity to cargo-borne neutrons are being investigated.

Four technologies have been identified as being currently commercially available and potential alternative neutron detectors to replace the use of ${ }^{3} \mathrm{He}$ in RPMs. These technologies are:

1) Boron trifluoride-filled proportional counters,

2) Boron-lined proportional counters,

3) Lithium-loaded glass fibers, and

4) Coated wavelength-shifting plastic fibers.

Reported here is a summary of the testing carried out at Pacific Northwest National Laboratory on these technologies to date, as well as measurements on ${ }^{3} \mathrm{He}$ tubes at various pressures. Details on these measurements are available in the referenced reports. Sponsors of these tests include the Department of Energy (DOE), Department of Homeland Security (DHS), the Department of Defense (DoD), and internal Pacific Northwest National Laboratory funds.

The purpose of this testing was to measure the efficiency and gamma sensitivity of the various neutron detection systems and configurations to determine which of these technologies could meet the neutron detection requirements while not exceeding the current footprint of the ${ }^{3} \mathrm{He}$-based neutron module in the RPMs. The measurements made as part of this testing included the response of each system to moderated neutrons and to a high gamma-ray exposure rate. As part of this testing, various configurations of ${ }^{3} \mathrm{He}-$ based detectors were also measured. The results reported here are from a limited set of tests to measure the capability of each technology listed above to meet the basic requirements. Additional requirements, such as robustness to different environmental conditions, would need to be tested prior to implementation.

The requirements used in this testing are from the specification for RPMs developed for the domestic deployments under the Radiation Portal Monitor Project (RPMP). These requirements allow for testing of individual modules with ${ }^{252} \mathrm{Cf}$, a common industrial neutron source. Simulations were performed that indicate the TSA system has comparable efficiency per unit surface area, and therefore if the technology meets the RPMP specification, it will likely meet the requirements of the Second Line of Defense (SLD) program for the TSA RPM in the same footprint of the current ${ }^{3} \mathrm{He}$ based module. However, development into the TSA configuration, and actual testing of the system, should be completed to verify compliance with the DOE requirements.

Use of an increased number of lower pressure ${ }^{3} \mathrm{He}$ tubes could reduce by $30 \%$ the amount of ${ }^{3} \mathrm{He}$ consumed in RPMs. This may not be relevant considering the current ${ }^{3} \mathrm{He}$ strategy for RPMs to find an alternative, however, it may be useful for other types of neutron detectors.

Page iv of ix 
Results from the boron trifluoride and boron-lined proportional counter tests indicate they can be configured to fit the current SAIC footprint and meet the neutron detection and gamma ray discrimination requirements. The coated wavelength shifting fibers are close to meeting the requirements for the tested configurations; while the lithium loaded glass (assuming appropriate scaling) is currently unable to meet the requirements. The vendors of both fiber technologies are working to meet the requirements for a fullscale RPM configuration, and at least the coated fiber technology is expected to meet the requirements by spring 2010.

If a technology is selected for further development for use in RPMs, additional work will be required to integrate the technology into a specific RPM system, and additional testing, including environmental testing, will be required before implementing into fielded systems to ensure the system continues to meet the entire suite of requirements. 


\section{Acronyms and Abbreviations}

$\begin{array}{ll}\text { ANSI } & \text { American National Standards Institute } \\ \text { atm } & \text { atmospheres } \\ \mathrm{BF}_{3} & \text { Boron trifluoride } \\ \mathrm{CBP} & \text { Customs and Border Protection } \\ \text { cps } & \text { counts per second } \\ \text { DHS } & \text { U.S. Department of Homeland Security } \\ \text { DoD } & \text { U.S. Department of Defense } \\ \text { DOE } & \text { U.S. Department of Energy } \\ \text { GARRn } & \text { Gamma Absolute Rejection Ratio in the presence of neutrons } \\ \text { GE } & \text { General Electric } \\ \text { IAT } & \text { Innovative American Technology } \\ \text { IPL } & \text { Isotope Products Laboratory } \\ \text { NNSA } & \text { National Nuclear Security Administration } \\ \text { PNNL } & \text { Pacific Northwest National Laboratory } \\ \text { PolyBox } & \text { polyethylene moderator/reflector box } \\ \text { PVT } & \text { polyvinyl toluene (plastic) scintillation gamma detector } \\ \text { RPM } & \text { Radiation Portal Monitor } \\ \text { RSP } & \text { Radiation Sensor Panel } \\ \text { SAIC } & \text { Science Applications International Corporation } \\ \text { SLD } & \text { Second Line of Defense }\end{array}$




\section{Contents}

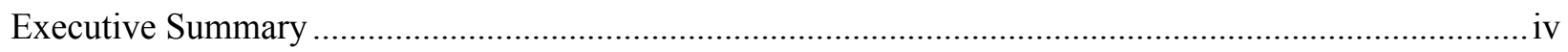

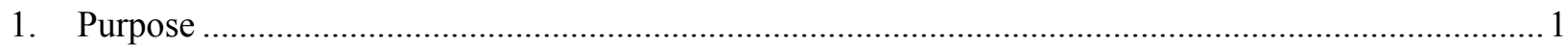

2. Alternative Neutron Detector Requirement .............................................................................2

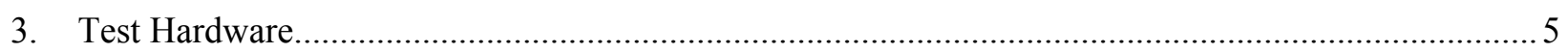

3.1. ${ }^{3}$ He Filled Proportional Neutron Detectors ........................................................................ 5

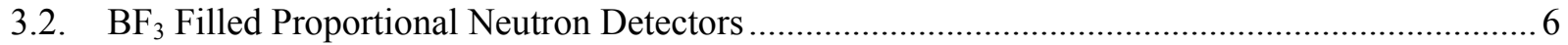

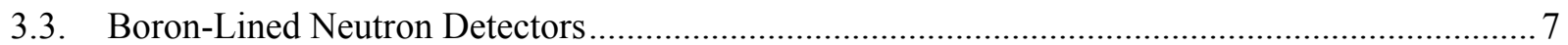

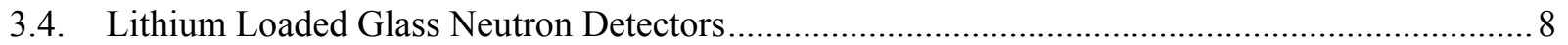

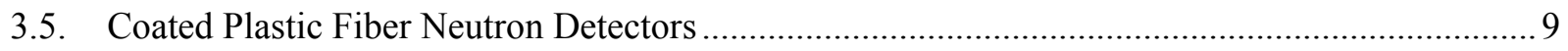

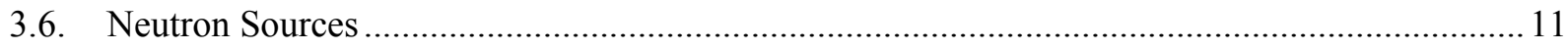

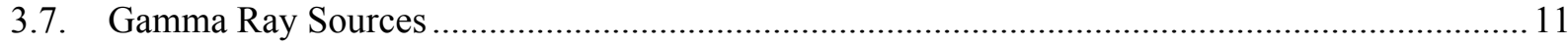

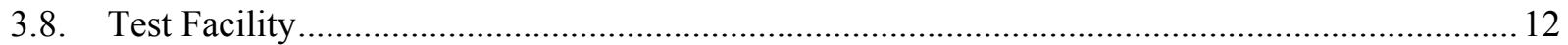

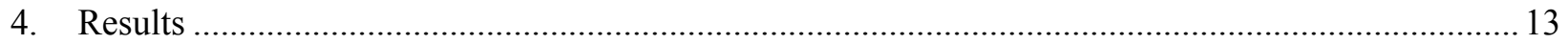

4.1. ${ }^{3}$ He Filled Proportional Tube Neutron Detectors ............................................................... 13

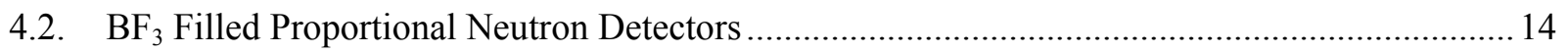

4.2.1. Absolute Neutron Efficiency $\mathrm{Of}^{\mathrm{BF}_{3}}$ Detectors ............................................................................

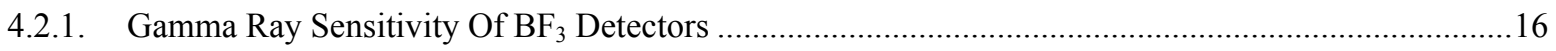

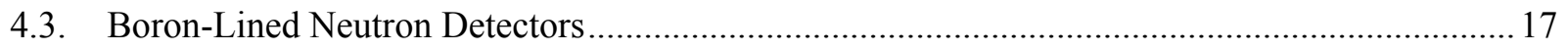

4.3.1. Modeling Results For Boron-Lined Detectors................................................................................17

4.3.2. Absolute Neutron Efficiency Of Boron-Lined Detectors .......................................................................17

4.3.3. Gamma Ray Sensitivity Of Boron-Lined Detectors .............................................................................19

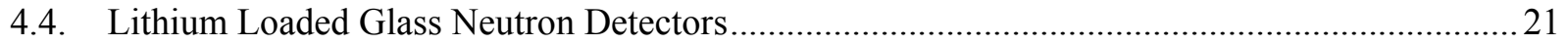

4.4.1. Absolute Neutron Efficiency Of Lithium Loaded Glass Detectors ......................................................21

4.4.2. Gamma Ray Sensitivity Of Lithium Loaded Glass Detectors ............................................................22

4.5. Coated Plastic Fiber Neutron Detectors .................................................................................... 24

4.5.1. Absolute Neutron Efficiency Of Coated Plastic Fiber Detectors ......................................................24

4.5.2. Gamma Ray Sensitivity Of Coated Plastic Fiber Detectors ..............................................................25

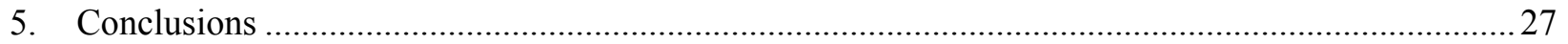

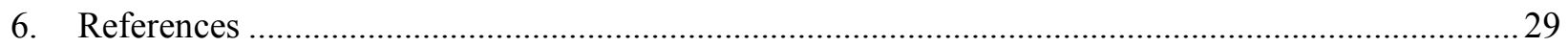

Additional Description of ${ }^{3} \mathrm{He}$ Filled Proportional Tube Neutron Detector Tests................................ 31

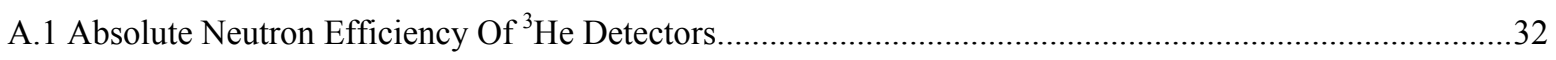

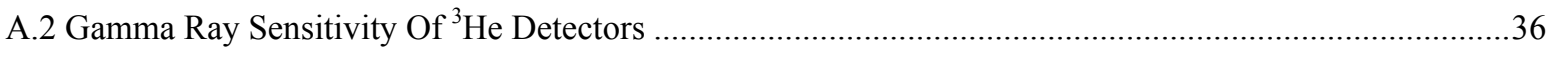




\section{Figures and Tables}

\section{Figures}

Figure 2.1. Views of One-Half of The SAIC (Left) and TSA (Right) MCNP Model Portal Monitors

Showing a Single Side of The Road From The Point of View of The Vehicle .................................. 3

Figure 3.1. Configuration of RPM (left) and Model System (right) on Prototype Re-Locatable Base. ....... 6

Figure 3.2. Top Cross-Section Views of RPM PolyBox with Two to Four Tubes Inserted......................... 7

Figure 3.3: Boron-Lined Detector Assembly Positioned for Static Tests Outside. .................................... 8

Figure 3.4: View of The Glass Fiber Detector Being Placed in The Moderator Box................................ 9

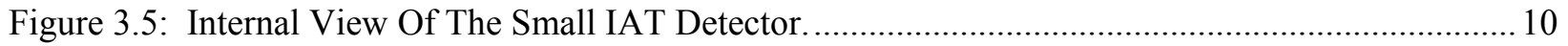

Figure 3.6: Internal View Showing Half of The Full-Scale IAT Detector and Electronics...................... 10

Figure 3.7: GE Reuter Stokes Detector Testing with Gamma Ray and Neutron Sources. ......................... 12

Figure 4.1. Results Of All Tests With Various Pressure ${ }^{3}$ He Tubes And Configurations......................... 13

Figure 4.2. Pulse Height Spectrum From $\mathrm{BF}_{3}$ Tubes..................................................................... 14

Figure 4.3. Absolute Efficiency as a Function of the Number of $\mathrm{BF}_{3}$ Tubes........................................ 15

Figure 4.4. Pulse Height Spectra of The Three-Tube $\mathrm{BF}_{3}$ Configuration................................................ 17

Figure 4.5: Modeling Result of Single Two-Inch Diameter Boron-Lined Tube Response to Neutrons (a), and Experimental Result for Response of Prototype I Detector System (b). ................................. 18

Figure 4.6: Neutron Efficiency Of Prototype I Detector System Under Different Test Scenarios Compared

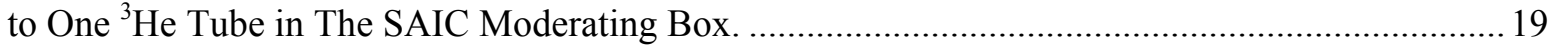

Figure 4.7: Boron Lined Tube Response to ${ }^{60} \mathrm{Co}$ Gamma Rays (Left); Scaled to Show Detail (Right)..... 20

Figure 4.8. Pulse Height Spectra for GE Reuter-Stokes Prototype II from The Gamma Ray Source........ 20

Figure 4.9: Approximate System Efficiency Calculated for The Nucsafe System Tested (Black=Liberal,

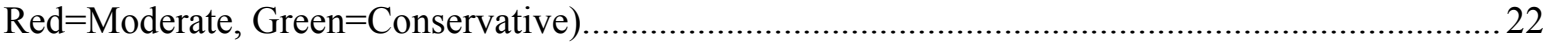

Figure 4.10: Efficiency of The Nucsafe Neutron Detector in Response to A Neutron Source and a Gamma

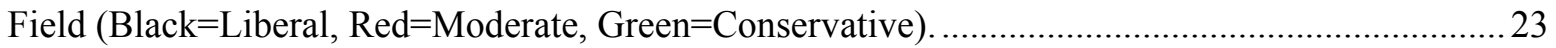

Figure 4.11. Pulse Height Spectra of The Four Detectors With Only The Neutron Source.......................25

Figure 4.12. Pulse Height Spectra of The Four Detectors with Neutron and Gamma Ray Source. ...........26

Figure A.1. Illustrative Pulse Height Spectra for Different Pressure ${ }^{3} \mathrm{He}$ Tubes. .................................... 31

Figure A.2. Efficiency Versus Partial Pressure from Second and Fourth Campaign. .............................. 33

Figure A.3. Data from All Tests (Top). Data Compared to Model as Function of Pressure (Bottom)......34

Figure A.4. Spectra Of ${ }^{3} \mathrm{He}$ Tube Response In The Presence Of A Large Gamma Source....................... 36 


\section{Tables}

Table 3.1. ${ }^{3} \mathrm{He}$ Tube Parameters............................................................................................................ 5

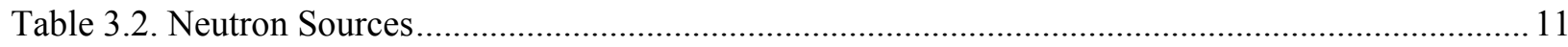

Table 4.1. Neutron Count Rates for Tested Configurations of $\mathrm{BF}_{3}$ Tubes. ............................................ 15

Table 4.2: Prototype II Absolute Efficiency, GARRn And Intrinsic Efficiency Versus Exposure Rate....21

Table 4.3: Absolute Efficiency, Intrinsic Gamma Ray Efficiency and GARRn at $10 \mathrm{mR} / \mathrm{h} \ldots \ldots \ldots \ldots \ldots \ldots \ldots . . . . . . .23$

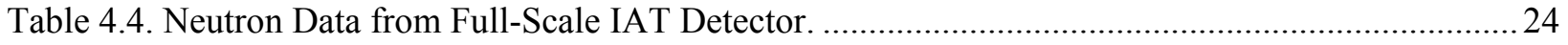

Table 4.5. Absolute Efficiency, GARRn And Intrinsic Gamma Ray Rejection Factor For Different Gamma Exposure Rates For The Full-Scale Detector With Threshold Of 43...............................26

Table 5.1. Summary of Performance of Neutron Detection Technologies..............................................27

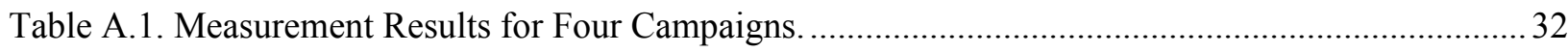

Table A.2. Estimated Photon Flux on a Single Tube ............................................................................ 37 


\section{Purpose}

Radiation portal monitor (RPM) systems used for interdiction of illicit materials at borders include highly sensitive neutron detection systems. The main reason for having neutron detection capability is to detect fission neutrons from plutonium. The currently deployed radiation portal monitors from TSA, Ludlum, and Science Applications International Corporation (SAIC) use neutron detectors based upon ${ }^{3} \mathrm{He}$-filled gas proportional counters, which are the most common large neutron detector (Kouzes et al., 2008).

Within the last few years, the amount of ${ }^{3} \mathrm{He}$ available for use in gas proportional counter neutron detectors has become limited, while the demand has significantly increased, especially for homeland security applications (Kouzes 2009a; Kouzes et al. 2009b). In the near future, the limited supply is expected to curtail use of ${ }^{3} \mathrm{He}$; therefore, alternative neutron detection technologies are being investigated for use in the radiation portal monitor systems being deployed for border security applications (Van Ginhoven et al., 2009).

From a survey of technologies, only four have been identified as currently commercially available, potential alternative neutron detectors to replace the use of ${ }^{3} \mathrm{He}$ in RPMs in the near-term. These technologies (and associated manufacturers) are:

1) Boron trifluoride $\left(\mathrm{BF}_{3}\right)$-filled proportional counters (from $\mathrm{LND}$ ),

2) Boron-lined proportional counters (from Reuter Stokes or LND),

3) Lithium-loaded glass fibers (from Nucsafe), and

4) Coated non-scintillating plastic fibers (from IAT).

Reported here is a summary of the testing carried out at Pacific Northwest National Laboratory (PNNL) on these technologies. The purpose of this testing was to measure the efficiency and gamma sensitivity of the various neutron detection system to determine which of these technologies could meet the specified neutron detection requirements. The measurements made as part of this testing included the response of each system to moderated neutrons and to a high gamma-ray exposure rate. The outcome was the identification of technologies for further investigation as an alternative to ${ }^{3} \mathrm{He}-b a s e d$ systems in deployed RPM systems. Sponsors of these tests include the Department of Energy (DOE), Department of Homeland Security (DHS), and the Department of Defense (DoD), as well as internal funds from Pacific Northwest National Laboratory (PNNL). The National Nuclear Security Administration (NNSA) NA-22 organization within DOE sponsored testing to help identify a technology solution for international deployments of RPMs carried out by the NA-25 organization. The Domestic Nuclear Detection Office within DHS, through the Radiation Portal Monitor Project, is interested in solutions for domestic RPMs, while the DoD has provided resources through the Guardian program. As this is a widespread issue affecting most neutron detection applications for national security, internal PNNL funding was also used to support the search for near-term alternatives.

The DHS and DoD program use similar RPMs (both currently deploying SAIC systems), and if a solution is identified for one program, it will likely be applicable for the other program. The DOE international program uses a different RPM, currently a TSA system. Since actual testing of the TSA configuration was not performed in this work, a comparison between the SAIC and TSA systems based upon simulations was used to relate the different configurations. This "scaling" relationship between the two configurations indicates that a solution for the DHS and DoD programs will also work for the international program. For this testing, the requirements for the DHS and DoD programs were used, since the testing can be performed with common industrial sources. 


\section{Alternative Neutron Detector Requirement}

There are a variety of RPMs used in the different government programs with varying capabilities. The main RPM used in the DHS and DoD programs is the SAIC system, and the neutron detection requirements are easily tested. The SAIC requirements allow static testing on a single neutron module, with ${ }^{252} \mathrm{Cf}$, a common industrial neutron source. Therefore, in the testing reported here, we used the SAIC neutron module configuration and requirements as the baseline for technology comparison, due to the ease of requirements testing and the availability of a SAIC system at PNNL.

Thus, the first constraint for the PNNL tests of any replacement of the current ${ }^{3} \mathrm{He}$-based neutron detector module in the SAIC RPMs used in the DHS and DoD programs was that it must fit within the space of, and have the same or better detection capability as, the present ${ }^{3} \mathrm{He}$-based modules. These SAIC systems were purchased under a specification (Stromswold et al., 2003) that originally required the use of ${ }^{3} \mathrm{He}$ and a single radiation sensor panel (RSP) to meet the following requirements:

"A ${ }^{252} \mathrm{Cf}$ neutron source will be used for testing neutron sensor sensitivity:

- To reduce the gamma-ray flux, the source shall be surrounded by at least $0.5 \mathrm{~cm}$ of lead. To moderate the neutron spectrum, $2.5 \mathrm{~cm}$ of polyethylene shall be placed around the source.

- The absolute detection efficiency for such $\mathrm{a}^{252} \mathrm{Cf}$ source, located $2 \mathrm{~m}$ perpendicular to the geometric midpoint of the neutron sensor, shall be greater than $2.5 \mathrm{cps} / \mathrm{ng}$ of ${ }^{252} \mathrm{Cf}$. The neutron detector center shall be $1.5 \mathrm{~m}$ above grade for this test. (Note: 10 nanograms of ${ }^{252} \mathrm{Cf}$ is equivalent to 5.4 micro-Ci or $2.1 \times 10^{4} \mathrm{n} / \mathrm{s}$, ${ }^{1}$ since ${ }^{252} \mathrm{Cf}$ has a $3.092 \%$ spontaneous fission (SF) branch and 3.757 neutrons/SF.)

- The neutron detector shall not generate alarms due to the presence of strong gamma-ray sources. The ratio of neutron sensor gamma-ray detection efficiency to neutron detection shall be less than 0.001."

To evaluate the performance of alternate neutron detectors compared to the baseline RPM, three criteria are considered: 1) neutron absolute detection efficiency, 2) intrinsic efficiency of gammas detected as neutrons, and 3) Gamma Absolute Rejection Ratio in the presence of neutrons (GARRn) (Kouzes et al., $2009 \mathrm{c}$ ). These are the basic radiation detection performance requirements a technology must meet, and additional requirements, such as robustness against environmental effects, would need to be evaluated for technologies that meet the basic requirements and are selected to be integrated into the RPM.

The neutron absolute detection efficiency $\left(\epsilon_{\text {abs }}\right)$ required is specified above as $2.5 \mathrm{cps} / \mathrm{ng}$ from a ${ }^{252} \mathrm{Cf}$ source at $2 \mathrm{~m}$ in the specified pig. The intrinsic efficiency of gamma rays detected as neutrons $\left(\epsilon_{\text {int }} \gamma_{n}\right)$ is defined as the number of events that are counted as neutrons in the presence of a gamma ray source divided by the number of photons hitting the entire detector surface area. The intrinsic efficiency of gamma rays detected as neutrons shall be less than or equal to $10^{-6}$ at an exposure rate of $10 \mathrm{mR} / \mathrm{h}$ for a detector configured to meet the neutron absolute detection efficiency. These values are selected based on the ANSI N42.35 standard (ANSI 2004) and the capability of ${ }^{3} \mathrm{He}$ based neutron detectors. The GARRn is the number of events that are counted as neutrons $\left(\epsilon_{\mathrm{abs} \gamma \mathrm{n}}\right)$ in the presence of both gamma ray and neutron sources divided by $\epsilon_{\mathrm{abs} n}$. Both of these measurements are made with the neutron source in the same position relative to the detector. The requirement for GARRn is $0.9 \leq$ GARRn $\leq 1.1$ at a $10 \mathrm{mR} / \mathrm{h}$

\footnotetext{
${ }^{1} 2.3 \times 10^{4} \mathrm{n} / \mathrm{s}$ is the current best known and used value
} 
gamma ray exposure rate. The GARRn requirement is to ensure the same neutron detection capability in the presence of a strong gamma ray source.

To extend the technology test results to other RPM configurations, specifically the TSA system used in the DOE Second Line of Defense (SLD) program, simulations were performed to evaluate the neutron detection capability of the SAIC and the TSA systems. For this purpose, a MCNP model of the TSA system was developed and its numerical results were used with results from a previously validated model of the SAIC system to compare the relative performance of these two systems. A computer rendering showing the front face of two models is shown in Figure 2.1, illustrating the system components on a single side of the roadway.

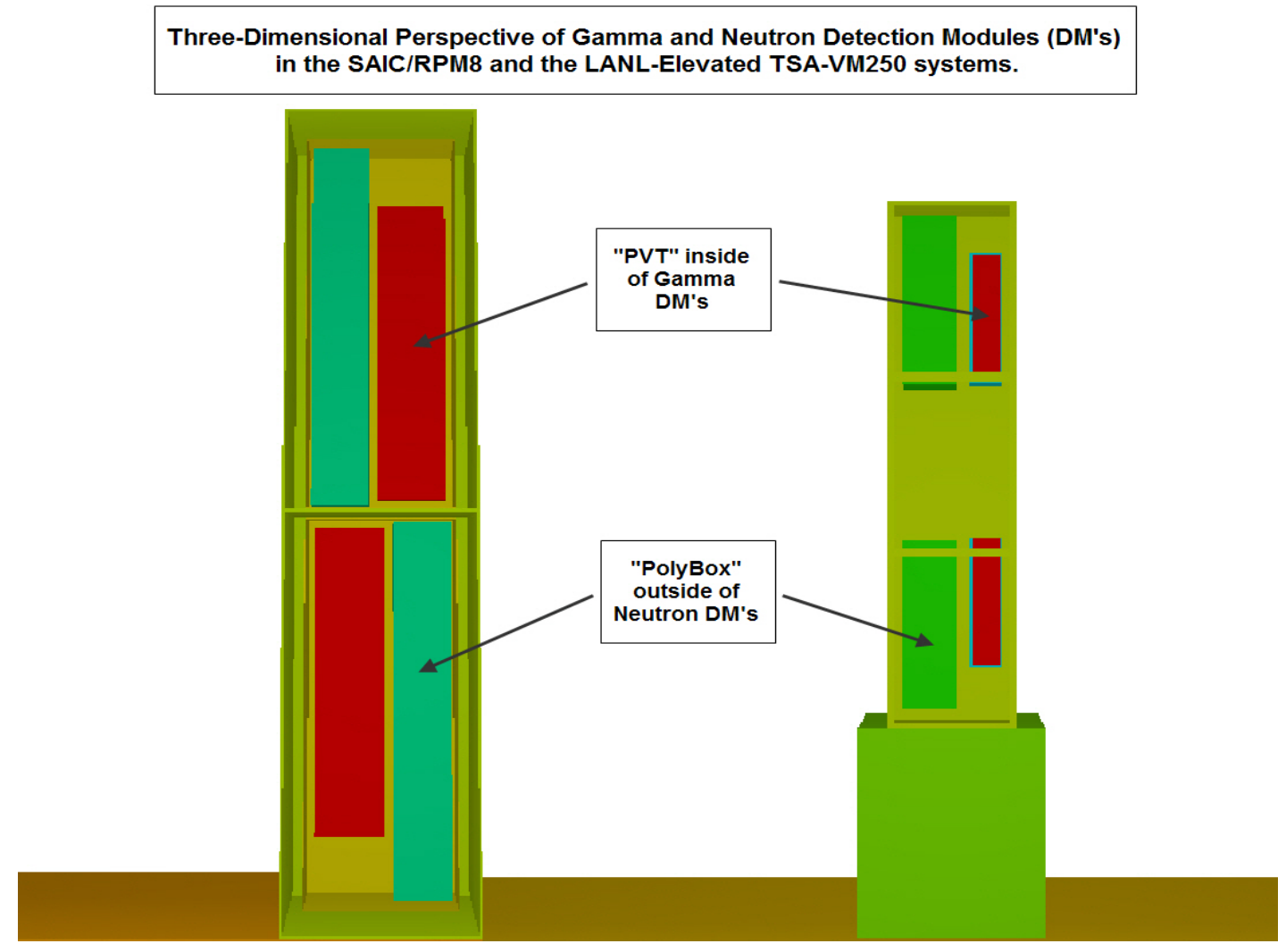

Figure 2.1. Views of One-Half of The SAIC (Left) and TSA (Right) MCNP Model Portal Monitors Showing a Single Side of The Road From The Point of View of The Vehicle.

The SAIC RPM system uses four neutron radiation detection modules for a typical cargo installation (two modules on each side of the roadway). The TSA vehicle portal system also contains four neutron modules. The neutron detection modules in both these systems consist of a hollow polyethylene box (or PolyBox) that functions as a neutron moderator and reflector for the ${ }^{3} \mathrm{He}$ tubes housed within it. A replacement technology will need to fit in the current footprint of the neutron detection modules and provide the same neutron detection capability provided by the current ${ }^{3} \mathrm{He}$ tubes. As can be seen from the Figure 2.1, the SAIC neutron detection modules, and therefore its detection capability is greater than the TSA capability. Thus any new technology that meets the SAIC detection requirement should also be able to meet the TSA requirement. A simulation of a ${ }^{252} \mathrm{Cf}$ source located $2 \mathrm{~m}$ in front of each neutron detection model was performed, and the absolute efficiency was calculated. The simulated efficiencies were close to the detector volume ratio between the two systems, so it is likely that if a new technology 
can meet the SAIC requirements, it will also do so in the TSA configuration. However, promising technologies will need to be tested in the TSA configuration. 


\section{Test Hardware}

Static testing was performed on all of the neutron detection technologies to determine response to neutrons and gamma rays. Dynamic testing was performed with some of the technologies to verify similar field of view capability, but is not reported here. In addition to the four sets of measurements performed related to the four alternative neutron detector technologies, measurements were made with tubes at various ${ }^{3} \mathrm{He}$ pressures. This was done to investigate alternative ${ }^{3} \mathrm{He}$ configurations to minimize ${ }^{3} \mathrm{He}$ use, validate the computer models, and to compare with the alternatives.

\section{1. $\quad{ }^{3} \mathrm{He}$ Filled Proportional Neutron Detectors}

The tests performed on ${ }^{3} \mathrm{He}$ tubes in the SAIC system described above were conducted with a total of six tubes, taken in pairs or individually (Kouzes et al. 2009d; Kouzes et al. 2009e; Kouzes et al. 2010a). These included two tubes filled with three atmospheres $(304 \mathrm{kPa})$ of ${ }^{3} \mathrm{He}$, two at one atmosphere $(101$ $\mathrm{kPa})$ tubes; and single tubes at two and two and one-half atmospheres (203-, 253-, and 304-kPa), all manufactured by LND. The three atmosphere $(304 \mathrm{kPa})$ tubes were manufactured in 2004 , while the other tubes were manufactured in 2009. The testing consisted of adding or swapping tubes in the SAIC PolyBox of the test-configured RSP (Figure 3.1). Table 3.1 gives the serial numbers and parameters for the six LND tubes tested. The ${ }^{3} \mathrm{He}$ partial pressures are given in $\mathrm{kPa}$ and atmospheres. Argon is used as an inert fill gas additive, plus $\mathrm{CO}_{2}$ is used in small amounts as a quench gas.

Table 3.1. ${ }^{3}$ He Tube Parameters

\begin{tabular}{|c|c|c|c|c|}
\hline Serial Number & $\begin{array}{c}{ }^{3} \mathrm{He} \text { Partial } \\
\text { Pressure, kPa (atm) }\end{array}$ & $\begin{array}{c}\text { Total } \\
\text { Pressure, kPa }\end{array}$ & Gas Mixture & $\begin{array}{c}\text { Recommended } \\
\text { Operating Voltage }\end{array}$ \\
\hline 325177 & $101(1.0)$ & 203 & ${ }^{3} \mathrm{He}, \mathrm{Ar}, \mathrm{CO}_{2}$ & 1151 \\
\hline 325180 & $101(1.0)$ & 203 & ${ }^{3} \mathrm{He}, \mathrm{Ar}, \mathrm{CO}_{2}$ & 1174 \\
\hline 325186 & $203(2.0)$ & 253 & ${ }^{3} \mathrm{He}, \mathrm{Ar}, \mathrm{CO}_{2}$ & 1014 \\
\hline 325183 & $253(2.5)$ & 253 & ${ }^{3} \mathrm{He}, \mathrm{CO}_{2}$ & 908 \\
\hline 102439 & $304(3.0)$ & 304 & ${ }^{3} \mathrm{He}, \mathrm{CO}_{2}$ & 1080 \\
\hline 102345 & $304(3.0)$ & 304 & ${ }^{3} \mathrm{He}, \mathrm{CO}_{2}$ & 1080 \\
\hline
\end{tabular}

Initially, the SAIC electronics were used to perform measurements. However, as other alternatives required the use of external electronics and, because of electronic problems with some tubes, external electronics were used in some measurements with the ${ }^{3} \mathrm{He}$ tubes. 

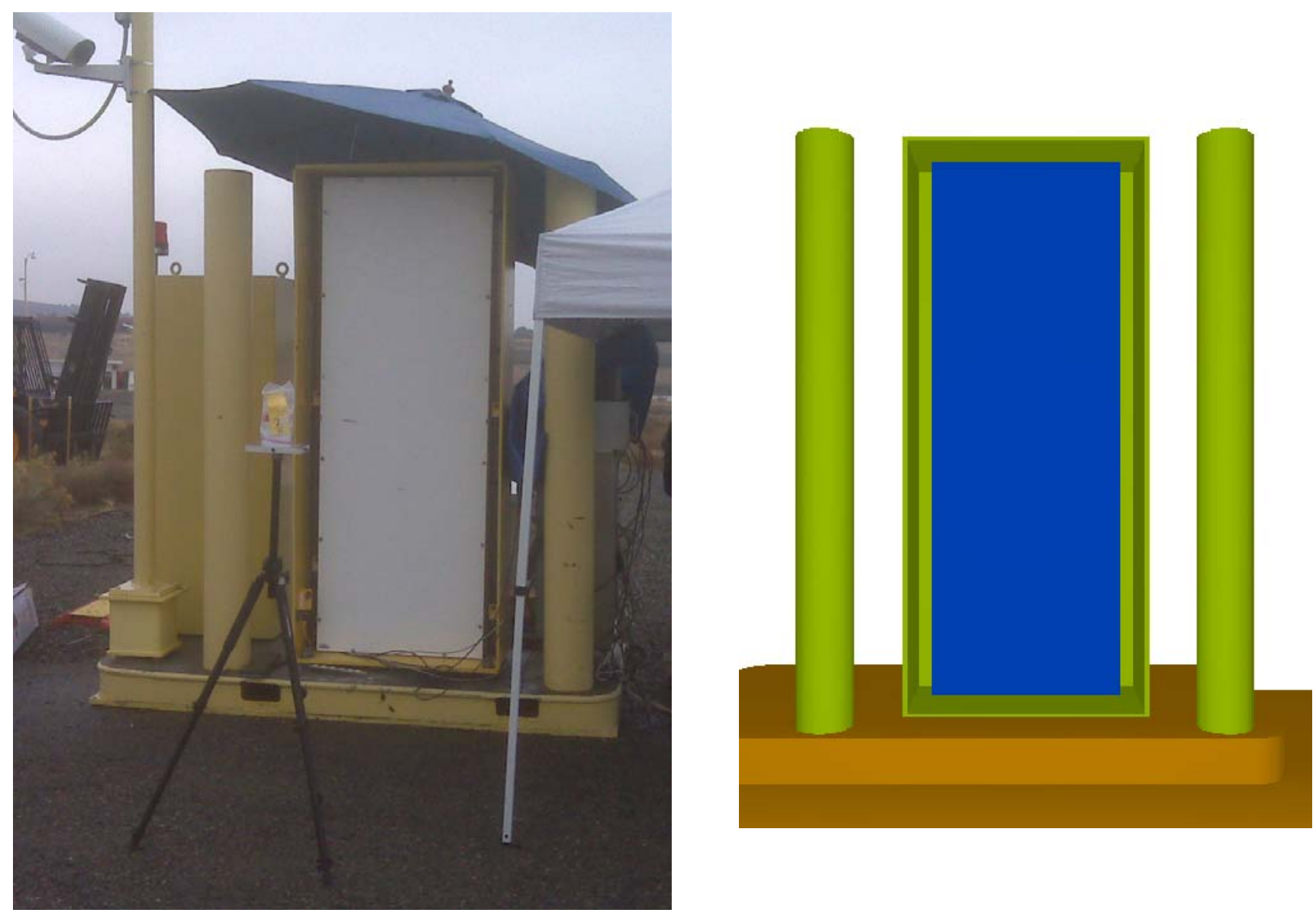

Figure 3.1. Configuration of RPM (left) and Model System (right) on Prototype Re-Locatable Base.

\section{2. $\quad \mathrm{BF}_{3}$ Filled Proportional Neutron Detectors}

The tests included one to four $\mathrm{BF}_{3}$ gas-filled stainless steel tubes (LND 253109) at $107 \mathrm{kPa}$ (800 torr or $1.05 \mathrm{~atm}$ ) placed into the SAIC PolyBox (Ely et al. 2009a; Kouzes et al. 2009f). Except for the different fill-gas, these are the same LND tube geometry used in the existing SAIC configuration. Some measurements were also made with $120 \mathrm{kPa}$ tubes, but those results are not presented here.

The $\mathrm{BF}_{3}$ gas provides the boron atoms as the neutron absorber and acts as the proportional gas that is used to detect the charged particles ( ${ }^{7} \mathrm{Li}$ ion and an $\alpha$ particle) that result from the ${ }^{10} \mathrm{~B}(\mathrm{n}, \alpha){ }^{7} \mathrm{Li}$ reaction.

The $\mathrm{BF}_{3}$ tubes were operated at $2300 \mathrm{~V}$, which exceeds the maximum voltage that can be supplied by the SAIC RPM system. The pulse shape from the $\mathrm{BF}_{3}$ tubes is also incompatible with the SAIC electronics. Thus, external signal processing electronics and multichannel analyzer were used to make the measurements instead of those in the SAIC system. The testing consisted of placing the tubes into the PolyBox of a SAIC RSP. Figure 3.2 shows a cross-sectional view of the configuration of two to four tubes in the SAIC standard or "Stock" PolyBox. The single tube configuration was consistent with the SAIC cargo configuration. 


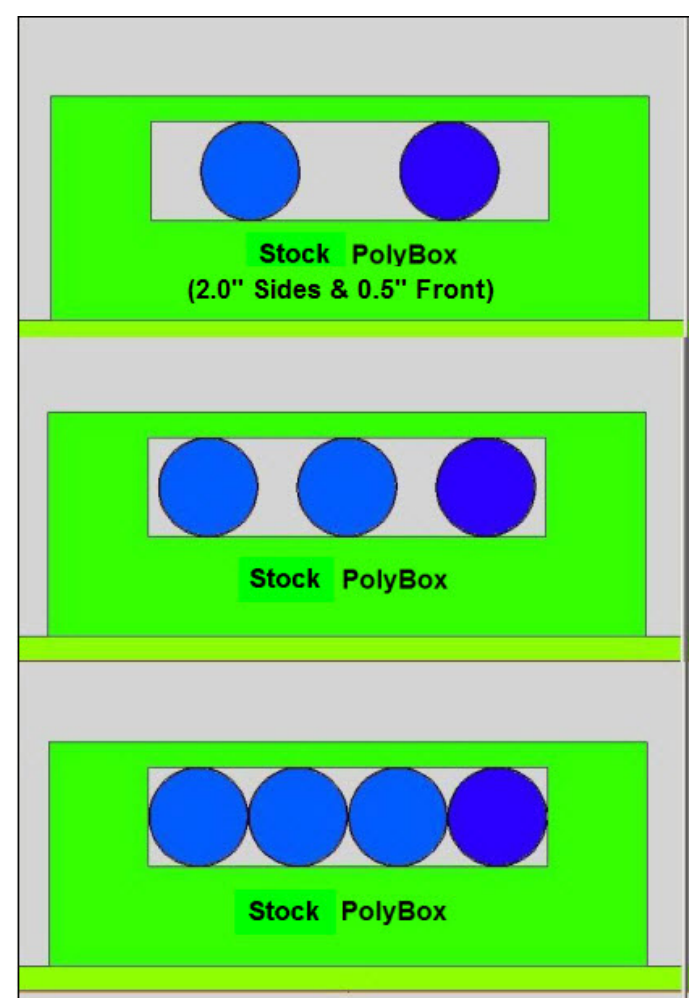

Figure 3.2. Top Cross-Section Views of SAIC PolyBox with Two to Four Tubes Inserted

\subsection{Boron-Lined Neutron Detectors}

General Electric (GE) Reuter Stokes provided two prototype boron-lined detector systems that were tested, where each prototype system the same size as an SAIC neutron detector module. Each prototype design utilizes multiple boron-lined proportional counters in a moderator assembly instead of individual 51-mm tubes (Lintereur et al. 2009a). Since the products need to escape the boron to interact with the proportional gas, only a thin layer of boron can be used, thus reducing the efficiency for neutron capture. The goal of the prototype development is to produce an assembly with comparable efficiency to a single ${ }^{3}$ He tube in the SAIC RPM, which requires maximizing the surface area of the boron. The assembly of boron-lined proportional counters from GE Reuter Stokes came completely enclosed within its own PolyBox as seen in Figure 3.3. The box was tested both outside and inside an SAIC RPM. Groups of tubes were connected together providing two connections outside the module, consistent with the SAIC electronics capability. However, external electronics were used for this testing, since the SAIC electronics would not accept the signals produced by the GE Reuter Stokes prototypes. A computer was used to accumulate the spectra. 


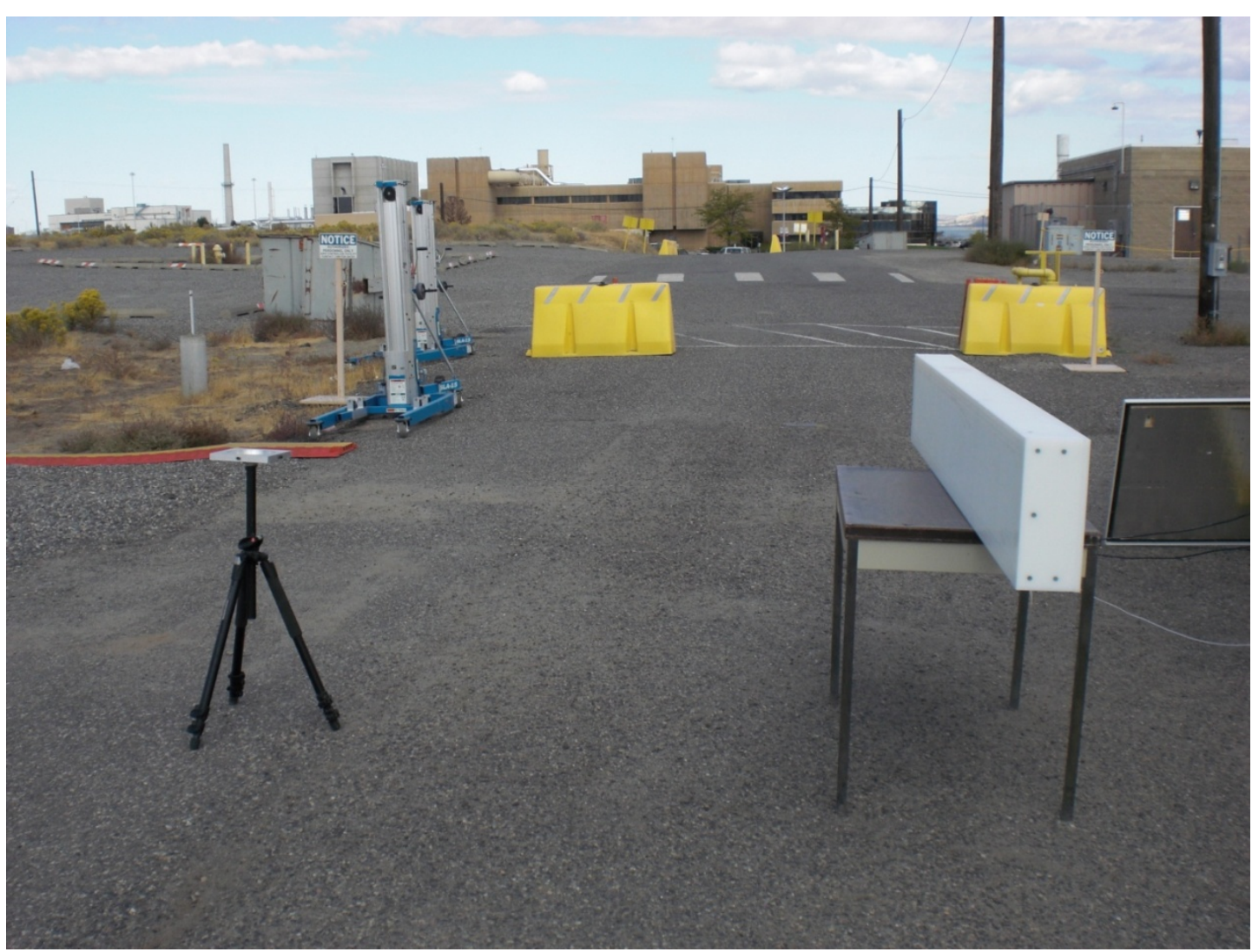

Figure 3.3: Boron-Lined Detector Assembly Positioned for Static Tests Outside.

\subsection{Lithium Loaded Glass Neutron Detectors}

The Nucsafe lithium loaded glass fiber detector tested was a small system from a backpack detector assembly. The ${ }^{6} \mathrm{Li}$ in the glass fiber serves as the thermal neutron absorber. Thermal neutrons result in charged particles from the ${ }^{6} \operatorname{Li}(\mathrm{n}, \alpha)^{3} \mathrm{H}$ reaction and the charged particles produce light in the fibers that is conducted to the photomultiplier tubes.

The neutron detector consists of three core sensors that are $50 \mathrm{~mm}$ wide by $0.275 \mathrm{~m}$ long by $25.4 \mathrm{~mm}$ deep (Ely et al. 2009b). There are 5 ribbons of glass fiber placed in the layers of each detector core utilizing approximately 2700 fibers/core. Each fiber detector is $150 \mu \mathrm{m}$ in diameter. The active area of the detector is $0.04125 \mathrm{~m}^{2}$ located in a $0.09 \mathrm{~m}^{2}$ aluminum box. The aluminum box is seen in Figure 3.4 being placed into its own PolyBox. This box was provided by NucSafe for the testing, as the backpack system does not contain a moderator (rather relying on the human body for moderation). The box has external dimensions of $0.26 \mathrm{~m} \times 0.50 \mathrm{~m} \times 0.10 \mathrm{~m}$ (the front surface area is $0.13 \mathrm{~m}^{2}$ ), with the polyethylene being $19 \mathrm{~mm}$ thick on the front and sides, and $38 \mathrm{~mm}$ thick on the back. Lead $(\sim 3.5 \mathrm{~mm})$ was included by the vendor on the front of the detector, inside the polyethylene box. The electronics for the detector process the signals produced by the fibers to provide the neutron count rate. These signals are processed through software filters to yield discrimination between neutron and gamma ray pulses. 


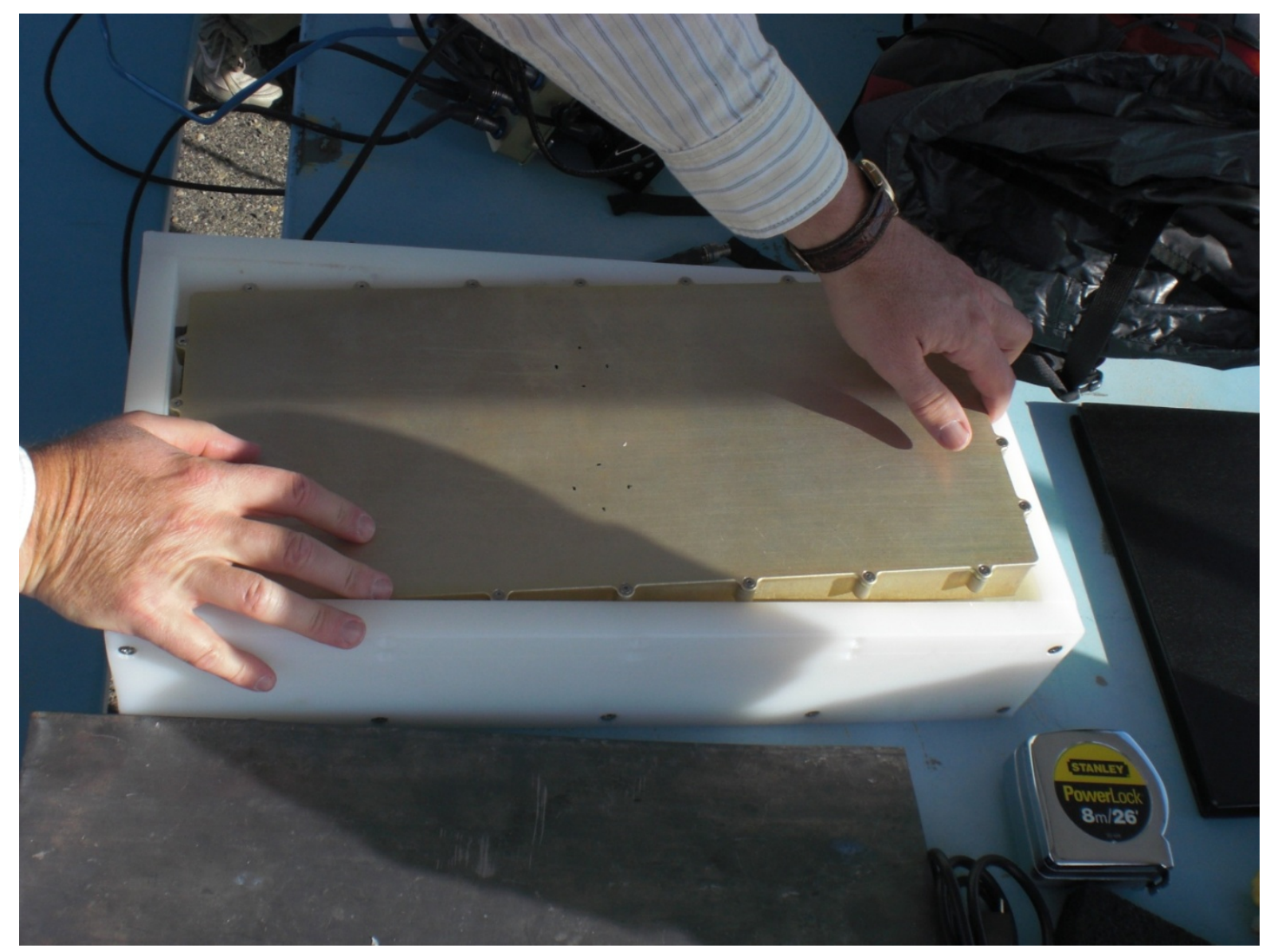

Figure 3.4: View of The Glass Fiber Detector Being Placed in The Box.

\subsection{Coated Plastic Fiber Neutron Detectors}

Two coated plastic fiber systems from IAT were tested (Lintereur et al. 2009b; Kouzes 2010b).

The IAT neutron detector uses wavelength-shifting plastic fibers (BC-704 from Saint Gobain) that are coated with ${ }^{6} \mathrm{Li} / \mathrm{ZnS}(\mathrm{Ag})$. The ${ }^{6} \mathrm{Li} / \mathrm{ZnS}(\mathrm{Ag})$ serves as neutron absorber and phosphor. Thermal neutrons interact via the ${ }^{6} \mathrm{Li}(\mathrm{n}, \alpha)^{3} \mathrm{H}$ reaction, and the resultant charged particles produce light in the zinc sulfide. The plastic wavelength shifting fibers conduct the light to the photomultiplier tubes.

For the first and smaller IAT system tested, the fibers are arranged side-by-side and the detector has four layers of fibers. The active width (coated) of the fiber array is $0.25 \mathrm{~m}$ and the active length is $0.25 \mathrm{~m}$. Fibers extend beyond the $0.25 \mathrm{~m}$ active length and are bundled at both ends into $51 \mathrm{~mm}$ ( 2 inch) diameter photomultiplier tubes. Figure 3.5 shows the (black) fiber array covered by the polyethylene moderator and the photomultiplier tubes. On one side of the fiber array the polyethylene is $0.25 \mathrm{~m} \times 0.25 \mathrm{~m} \times 0.05$ $\mathrm{m}$ (2-inch) thick and on the other side it is $0.25 \mathrm{~m} \times 0.25 \mathrm{~m} \times 0.38-\mathrm{m}$ (1.5-inch) thick.

Signals from the photomultiplier tubes are digitized, and pulse-shape analysis yields discrimination between neutron and gamma ray pulses. Gamma-ray pulses are narrower than neutron pulses (neutron pulses have a longer decay time due to the interaction mechanism) and have a faster rise time as calculated by averaging over several channels at the beginning of individual pulses. 


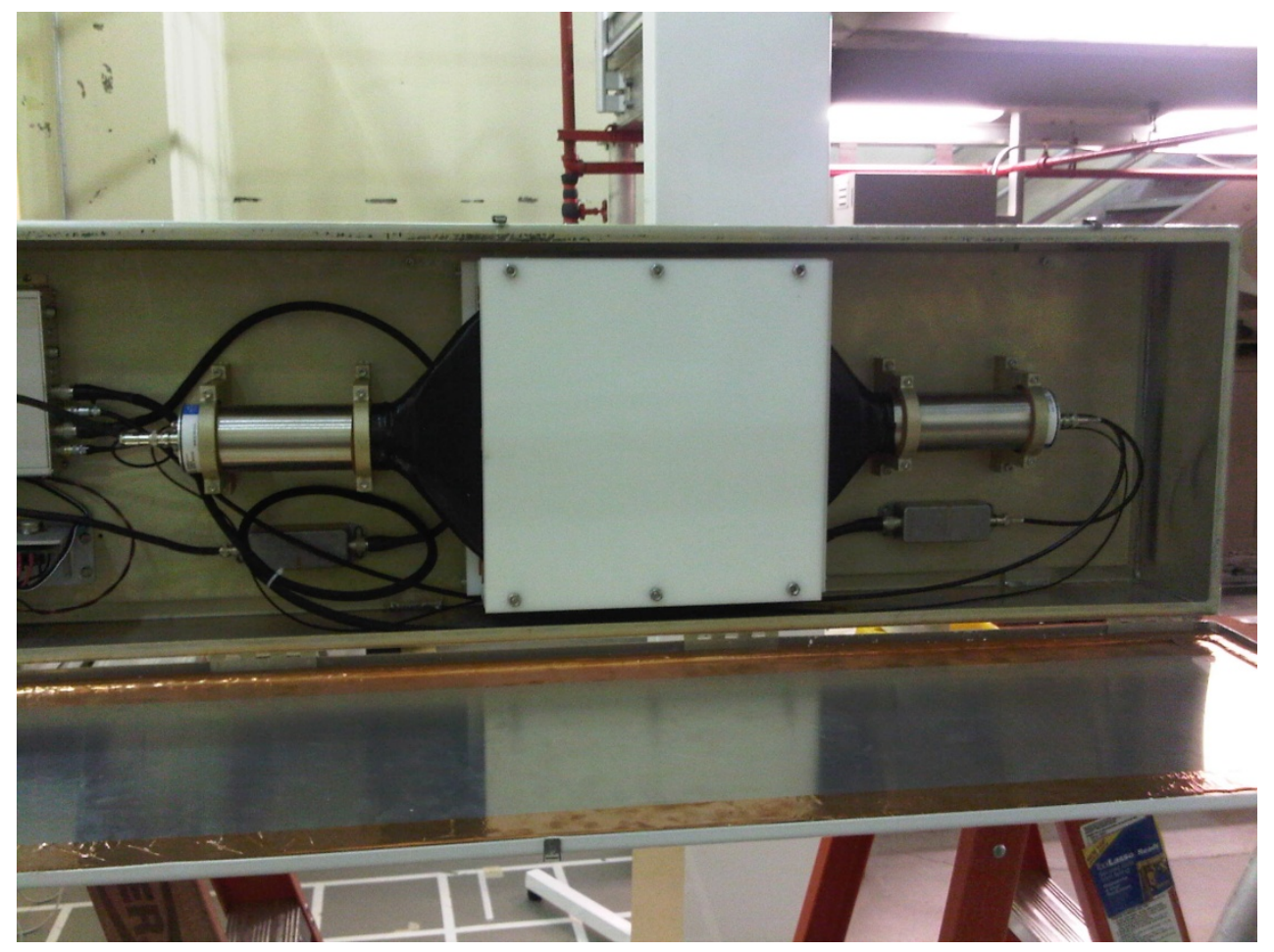

Figure 3.5: Internal View Of The Small IAT Detector.

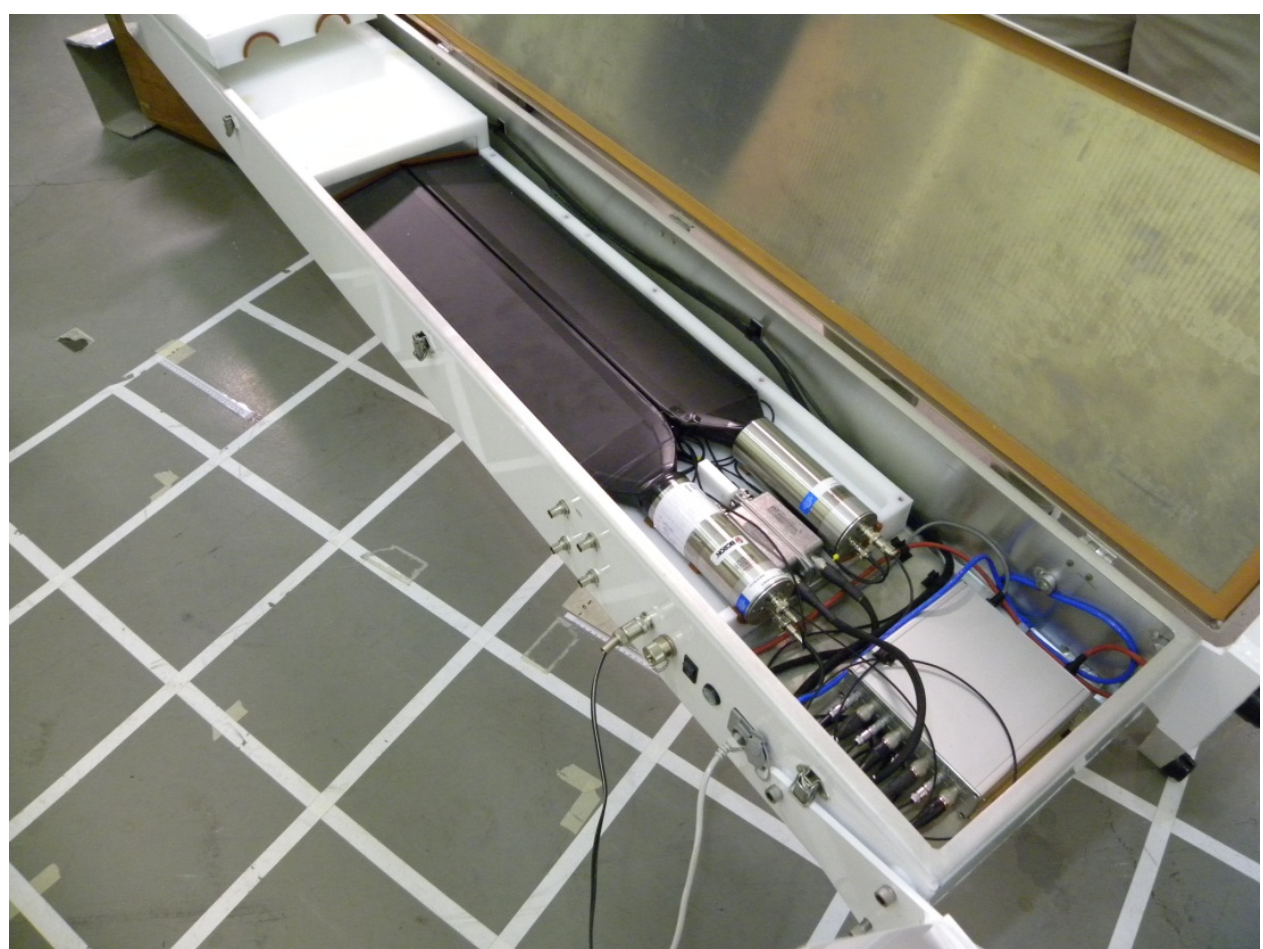

Figure 3.6: Internal View Showing Half of The Full-Scale IAT Detector and Electronics. 
The larger IAT system tested had four "paddles," each of which is $0.127 \mathrm{~m}$ by $0.635 \mathrm{~m}$ ( 5 inch x 25 inch) with one phototube at the end. These paddles are mounted in a polyethylene box with $28.6 \mathrm{~mm}(1.125$ inch) walls on all sides. Figure 3.6 shows two of the paddles and the photomultiplier tubes in the polyethylene moderator box. The electronics for the detector (shown at the top of Figure 3.6) process the signals to provide the neutron count rate. This larger system has a footprint that is consistent with the current ${ }^{3} \mathrm{He}$ neutron module in the SAIC system.

\subsection{Neutron Sources}

The neutron sources used for these tests were ${ }^{252} \mathrm{Cf}$ sources purchased from the Eckert \& Ziegler Isotope Products Laboratory (IPL) in Valencia, CA. A typical source composition was $93.832 \%{ }^{252} \mathrm{Cf}, 0.0309 \%$ ${ }^{251} \mathrm{Cf}$, $6.016 \%{ }^{250} \mathrm{Cf}$, and $0.117 \%{ }^{249} \mathrm{Cf}$ according to IPL. Table 3.2 gives the sources used for the various tests.

Table 3.2. Neutron Sources

\begin{tabular}{|c|c|c|c|c|c|}
\hline $\begin{array}{c}\text { PNNL } \\
\text { Source } \\
\text { Number }\end{array}$ & Test & $\begin{array}{c}\text { Calibration } \\
\text { Activity } \\
(\mu \mathrm{Ci})\end{array}$ & Calibration Date & Test Date & $\begin{array}{c}\text { Activity on } \\
\text { Test Date } \\
(\mu \mathrm{Ci})\end{array}$ \\
\hline \multirow[t]{3}{*}{$60208-16$} & Plastic fiber & $20.0 \pm 3.0$ & \multirow{3}{*}{$\begin{array}{c}\text { February } 15, \\
2009\end{array}$} & August 7, 2009 & $20.2 \pm 1.15 *$ \\
\hline & ${ }^{3} \mathrm{He}$ & $20.0 \pm 3.0$ & & August 10, 2009 & $20.1 \pm 1.25 *$ \\
\hline & Glass fiber & $20.0 \pm 3.0$ & & September 8, 2009 & $19.7 \pm 1.15 *$ \\
\hline 60208-40D & Boron-lined & $20.0 \pm 3 \mu \mathrm{Ci}$ & June 5, 2009 & $\begin{array}{c}\text { October 1-2, } 2009 \\
\text { October 7, } 2009\end{array}$ & $20.3 \pm 1.25 *$ \\
\hline \multirow[t]{7}{*}{$60208-44$} & ${ }^{3} \mathrm{He}$ & $21.91 \pm 1.25$ & \multirow{7}{*}{ October 1, 2009} & October 21, 2009 & $21.6 \pm 1.25$ \\
\hline & $\mathrm{BF}_{3}$ & $21.91 \pm 1.25$ & & October 21, 2009 & $21.6 \pm 1.25$ \\
\hline & ${ }^{3} \mathrm{He}$ & $21.91 \pm 1.25$ & & November 5, 2009 & $21.4 \pm 1.25$ \\
\hline & ${ }^{3} \mathrm{He}$ & $21.91 \pm 1.25$ & & November 9, 2009 & $21.3 \pm 1.25$ \\
\hline & Plastic fiber & $21.91 \pm 1.25$ & & December 18,2009 & $20.7 \pm 1.25$ \\
\hline & Plastic fiber & $21.91 \pm 1.25$ & & January 12,2010 & $20.4 \pm 1.25$ \\
\hline & $\begin{array}{c}\text { Plastic fiber } \\
\& \text { Boron- } \\
\text { lined }\end{array}$ & $21.91 \pm 1.25$ & & February 23,2010 & $19.8 \pm 1.25$ \\
\hline
\end{tabular}

* Values on test dates are recalibrated value cross-referenced to the NIST-calibrated source 60208-44

\subsection{Gamma Ray Sources}

The gamma source used for the gamma insensitivity testing for the ${ }^{3} \mathrm{He}$ and $\mathrm{BF}_{3}$ tubes was a commercial ${ }^{192}$ Ir radiography source. This source was brought to PNNL by an external contractor and was stated to be $24.2 \mathrm{Ci}$ at the time of the testing. The ${ }^{192} \mathrm{Ir}$ source was used as it provides a number of gamma energies to provide a broad energy spectrum. The broad energy spectrum is the most commonly expected large gamma source that would be encountered in homeland security applications, either from an active naturally occurring radioactive material (NORM) source or a shielded industrial or medical source. A calibrated dose meter was used to measure the dose at the face of the RSP when the radiography source was exposed.

A ${ }^{60}$ Co source was used for the gamma sensitivity tests on all the other systems. Measurements were made in Building 318 at PNNL with the gamma-ray source by itself and the gamma-ray source with a neutron source placed $2 \mathrm{~m}$ from the detector. The ${ }^{60} \mathrm{Co}$ gamma source is stored in a vault for the 'closed' 
position and moved remotely on a pneumatic shuttle system into the center of the room for the 'open' position. The exposure rates at the detector, ranging from $10 \mathrm{mR} / \mathrm{h}$ to $100 \mathrm{mR} / \mathrm{h}$, were provided by measurements made by the staff at Building 318. The source activity on the day of the tests was determined by calculating the source strength necessary to deliver the measured dose rate at each position based on a reference measurement at one position. A $10 \mathrm{mR} / \mathrm{h}$ exposure rate for the ${ }^{60} \mathrm{Co}$ gamma source corresponds to $\sim 4500$ photons per second per $\mathrm{cm}^{2}$, which produced $\sim 10^{8}-10^{9}$ photons per second on the detectors.

Figure 3.7 shows a system set up for testing near the gamma ray and neutron sources. The gamma-ray source is the vertical tube at the center of the disk in the foreground, and the neutron source can be seen on a tripod behind the detector with the top of the source showing above the detector that is positioned horizontally.

\subsection{Test Facility}

The tests were performed at the $331 \mathrm{G}$ Integration Test Facility and in the 318 Building, both located at PNNL in Richland, WA.

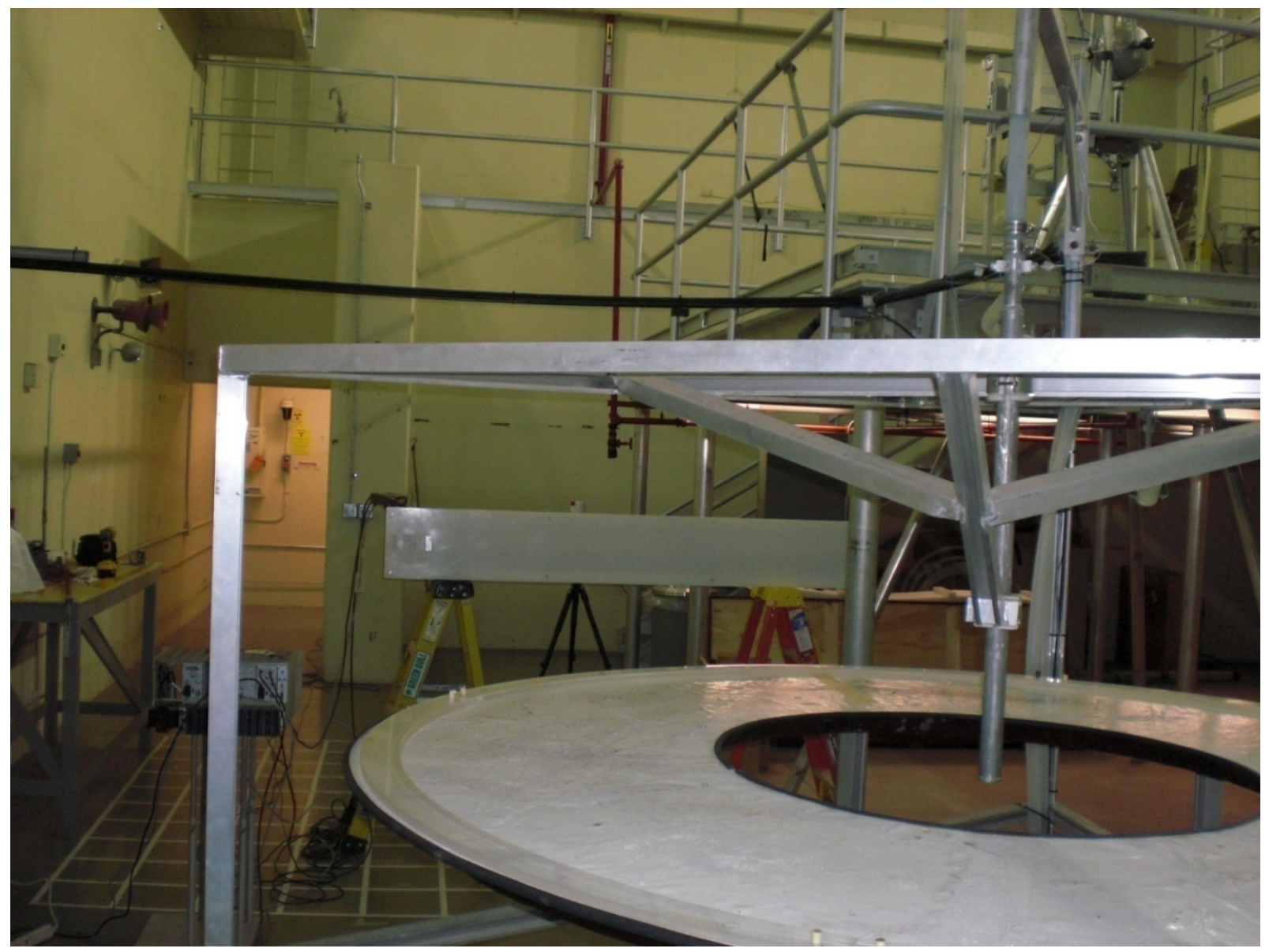

Figure 3.7: GE Reuter Stokes Detector Testing with Gamma Ray and Neutron Sources. 


\section{Results}

\section{1. $\quad{ }^{3} \mathrm{He}$ Filled Proportional Tube Neutron Detectors}

Between the dates of August 10, 2009 and November 9, 2009, four campaigns of test measurements were carried out on ${ }^{3} \mathrm{He}$ tubes having partial pressures of 101, 203, 253, and $304 \mathrm{kPa}(1,2,2.5$, and $3 \mathrm{~atm})$. Summarized here are the results presented in Kouzes et al. (2009e). For the first test, SAIC electronics were used, while for the second through fourth test campaigns, external electronics were used. Multiple tests were made initially because of problems with the electronics, apparent high voltage break down in the tubes, and the need to resolve variations seen in the data from tubes that were nominally of the same pressure. The error bars on the measurements result mostly from the $5.7 \%$ uncertainty associated with the NIST traceable source described above. Measurements were made with the neutron source within the pig for all tests, and the first test also used the unmoderated source.

Figure 4.1 provides a summary for the all the tests with ${ }^{3} \mathrm{He}$ tubes, with additional details provided in Appendix A. The highest efficiency (top points) is obtained with two-tube configurations. The horizontal dashed line is the required efficiency. Of interest is the two-tube configuration at one atmosphere, as this configuration exceeds the specification. This configuration has similar response as the single tube at three atmospheres, but contains $1 / 3$ less gas. Another alternative to minimize the ${ }^{3} \mathrm{He}$ gas usage may be to slightly lower the pressure in a single tube configuration, since the tube at three atmospheres somewhat exceeds the specification.

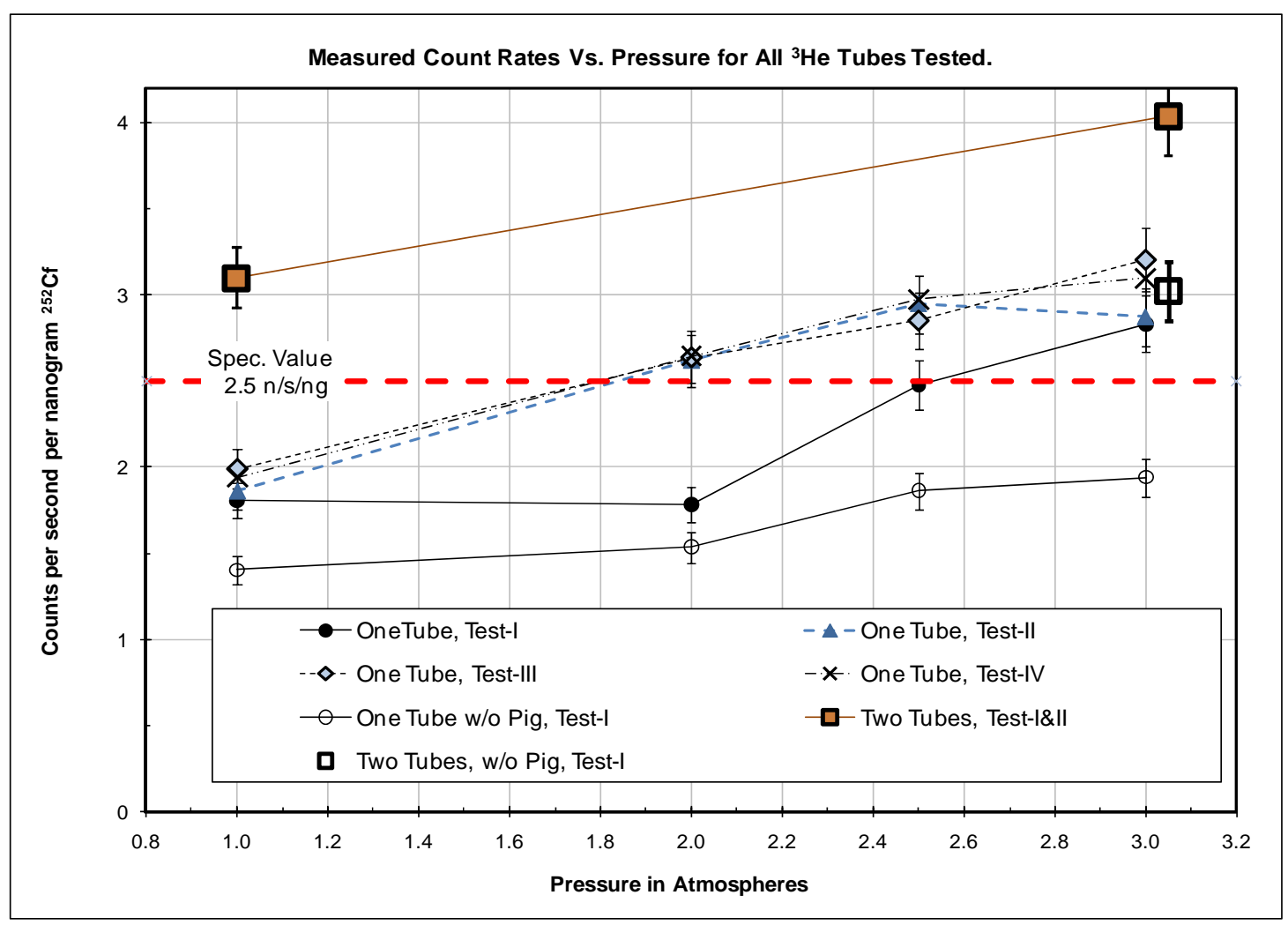

Figure 4.1. Results Of All Tests With Various Pressure ${ }^{3}$ He Tubes And Configurations. 
Tests with a gamma-ray source were also conducted and details provided in Appendix A. The gammaray discrimination for the tested ${ }^{3} \mathrm{He}$ tubes was as expected and meets the detection efficiency of $10^{-6}$ at $10 \mathrm{mR} / \mathrm{hr}$.

\section{2. $\quad \mathrm{BF}_{3}$ Filled Proportional Neutron Detectors}

Measurements of the neutron detection efficiency for one to four $\mathrm{BF}_{3}$ tubes were made (Kouzes et al. 2009f) as were measurements of the gamma ray sensitivity (Ely et al. 2009a).

\subsubsection{Absolute Neutron Efficiency Of $\mathrm{BF}_{3}$ Detectors}

Measurements of the efficiency for one to four $\mathrm{BF}_{3}$ tubes with the moderated source at a distance of $2 \mathrm{~m}$ from the detector were made (Kouzes et al. 2009f). Figure 4.2 shows a spectrum of the pulse height from the two $\mathrm{BF}_{3}$ tubes located in the SAIC polyethylene moderator box (in the steel housing). The observed peak is not as symmetric as that observed with ${ }^{3} \mathrm{He}$ tubes due to the physics of the tube.

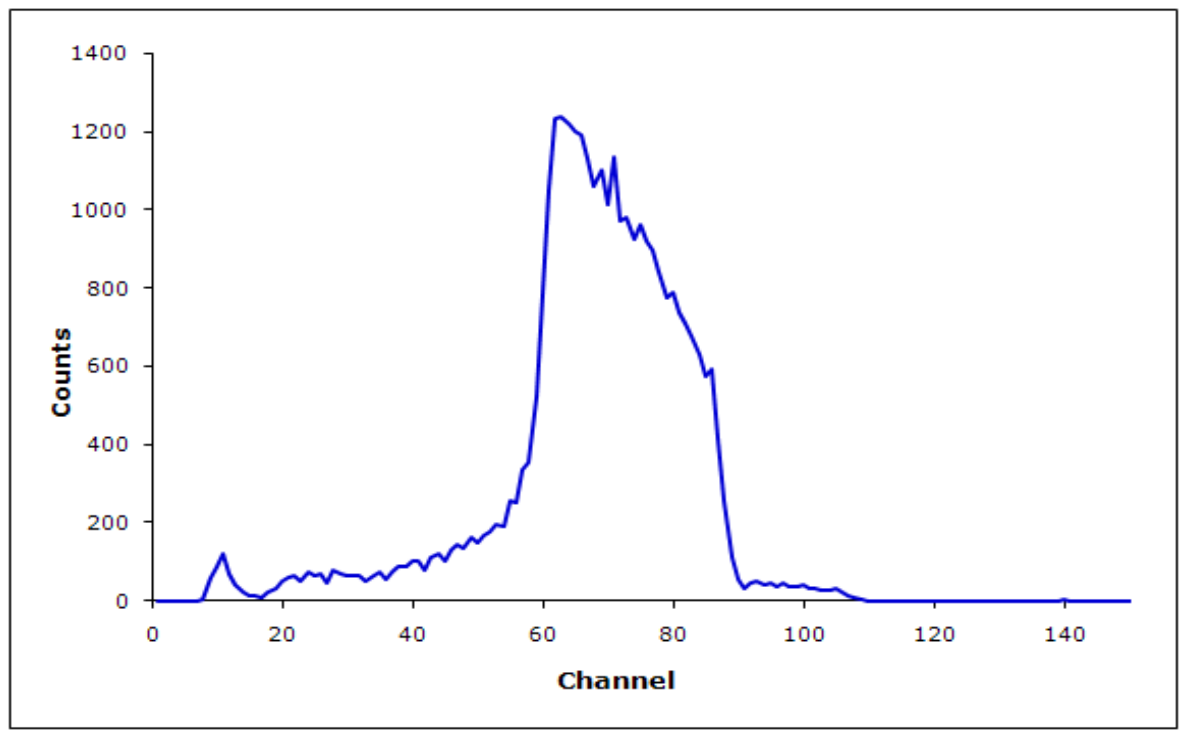

Figure 4.2. Pulse Height Spectrum From $\mathrm{BF}_{3}$ Tubes.

Since only two data acquisition channels existed only two of the tubes were instrumented for the configurations with three and four tubes. The analysis for the three and four tube measurements was performed, assuming that the tubes responded symmetrically. Thus, the uninstrumented one or two tubes were accounted for by adding the matching instrumented tube twice to the total counts. This potentially introduces a small error to the results. Table 4.1 shows the data obtained, including the counts per second (cps) values for the two tubes that were instrumented (cps/2-tubes) and for all the tubes (cps All Tubes) in the measurements (one pair plus one tube or two pairs). This total was converted to counts per second per nanogram of ${ }^{252} \mathrm{Cf}$ source material to compare with the specified value of $2.5 \mathrm{cps} / \mathrm{ng}$. The last two columns show the values obtained previously with the $120 \mathrm{kPa}$ (1.18 atm; 900 torr) $\mathrm{BF}_{3}$ tubes (Ely et al. 2009a), where the "Corrected" column has been scaled to correct for the recalibrated ${ }^{252} \mathrm{Cf}$ source strength (from $9 \mu \mathrm{Ci}$ to $8 \mu \mathrm{Ci}$ on the measurement date). 
Figure 4.3 shows a graph of the absolute neutron efficiency, where the upper curve is the results from the $107 \mathrm{kPa}$ (1.06 atm; 800 torr) tubes; the middle curve from the source-corrected $120 \mathrm{kPa}$ tube (Ely et al. 2009a); and the lowest curve from the MCNP simulations. The absolute efficiencies from the simulations are about $10-15 \%$ less than the measured values. The uncertainty in the latest results is dominated by the source strength uncertainty of $5.7 \%$, while the earlier data had a $10 \%$ uncertainty. These latest results indicate that two $\mathrm{BF}_{3}$ tubes at $107 \mathrm{kPa}$ can (marginally) meet the required efficiency (horizontal red line in the figure) as specified by Stromswold et al. (2003).

This result differs from the result reported previously for the $120 \mathrm{kPa}$ tubes (Ely et al. 2009a) and this difference can be partially attributed to the larger $(\sim 15 \%)$ source uncertainty in the earlier measurements. There may also have been an impact from the electronics used in the previous measurements. External electronics were used to supply the high voltage in both of the tests, but the multichannel analyzers differed between the $107 \mathrm{kPa}$ and $120 \mathrm{kPa}$ measurements, with potentially different dead times and thresholds.

Table 4.1. Neutron Count Rates for Tested Configurations of $\mathrm{BF}_{3}$ Tubes.

\begin{tabular}{|c|c|c|c|c|c|}
\hline \# Tubes & cps/2-tubes & cps All Tubes & $107 \mathrm{kPa}$ cps/ng & $120 \mathrm{kPa}^{1} \mathrm{cps} / \mathrm{ng}$ & $\begin{array}{c}\text { Corrected } \\
120 \mathrm{kPa} \text { cps/ng }\end{array}$ \\
\hline 1 & 65 & 65 & 1.6 & 1.4 & 1.58 \\
\hline 2 & 107 & 107 & 2.7 & 2.3 & 2.59 \\
\hline 3 & 86 & 131 & 3.3 & 2.7 & 3.04 \\
\hline 4 & 75 & 150 & 3.7 & 3.0 & 3.38 \\
\hline
\end{tabular}

${ }^{1}$ data from (Ely et al. 2009a)

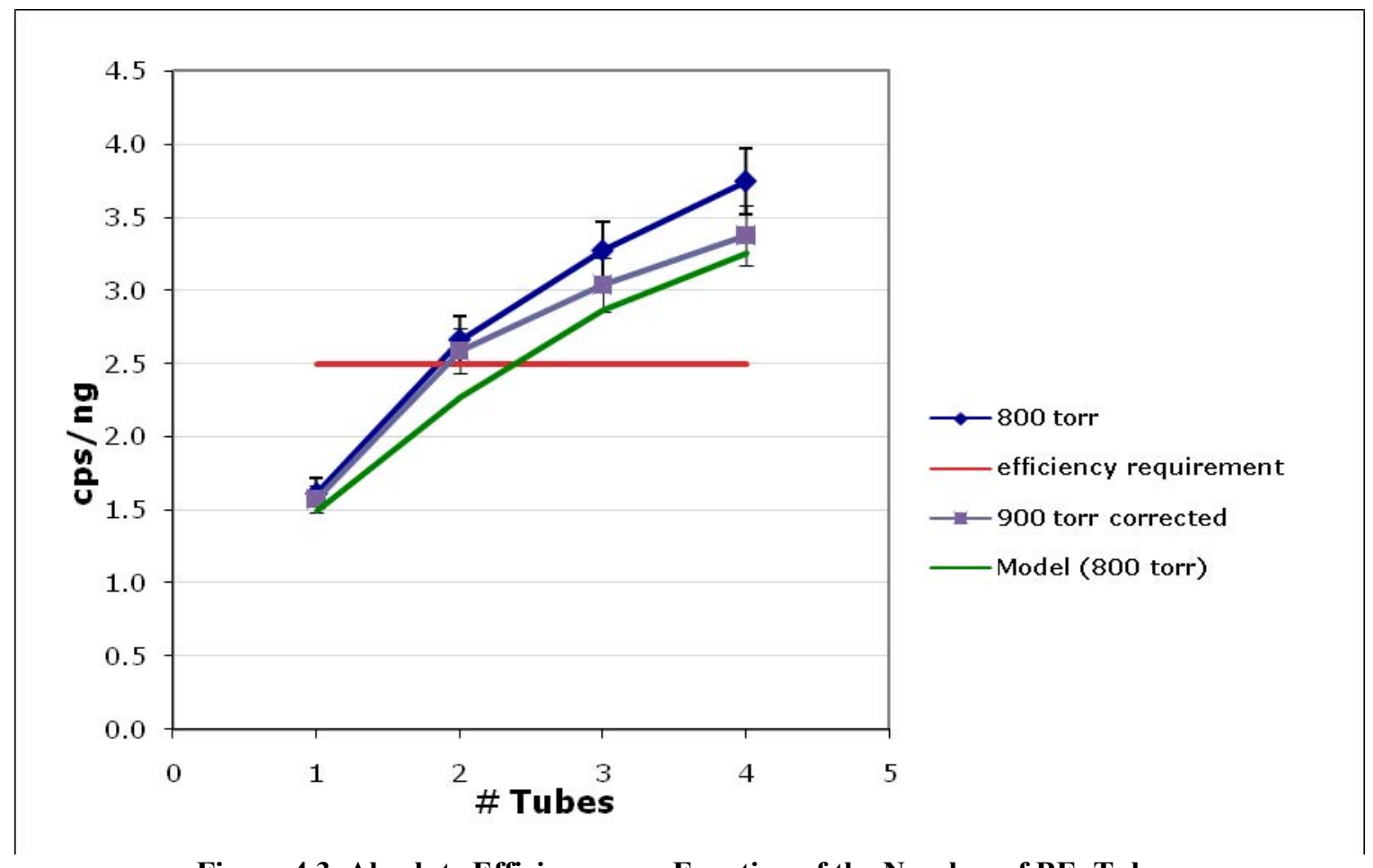

Figure 4.3. Absolute Efficiency as a Function of the Number of $\mathrm{BF}_{3}$ Tubes.

The neutron source used in the measurements for the $107 \mathrm{kPa}$ (800 torr) tubes was used to cross calibrate the neutron source used for the previous measurements on the $120 \mathrm{kPa}$ (900 torr) tubes. This cross 
calibration was accomplished by making measurements with both sources in the same geometry and a ${ }^{3}$ He-based neutron detector. This measurement showed that the source strength used by Ely et al. (2009a) was apparently lower than implied by its calibration. The scaled calibration gives a source strength of 8 $\mu \mathrm{Ci}$ at the time of the $120 \mathrm{kPa}$ (900 torr) measurements (June 30, 2009) rather than the $9 \mu \mathrm{Ci}$ used in the previous paper (Ely et al. 2009a). The earlier results were corrected with the new source strength and the scaled data for the $120 \mathrm{kPa}$ (900 torr) tubes are shown in Table 4.1 and Figure 4.3. The two sets of measurements have overlapping uncertainties, but it was expected that the $120 \mathrm{kPa}$ (900 torr) tubes would have a higher absolute efficiency than the $107 \mathrm{kPa}$ (800 torr) tubes in disagreement with these results. This may be from the differences in the electronics mentioned above, or the fact that the $107 \mathrm{kPa}$ tubes are newer and from a different manufacturer. It would be of value to test $\mathrm{BF}_{3}$ tubes at even lower pressures to see the dependence of efficiency on pressure. Higher pressures are of less interest since they require even higher voltages to operate and additional shipping limitations on pressurized cylinders come into play.

The experimental measurements with $\mathrm{BF}_{3}$ tubes at $107 \mathrm{kPa}$ (800 torr) indicate that two $107 \mathrm{kPa}$ (800 torr) tubes may be sufficient to replace one three-atmosphere ${ }^{3} \mathrm{He}$ tube in a standard SAIC moderator box, but likely not for any lower $\mathrm{BF}_{3}$ pressure. Because this conclusion is based upon results that appear just barely above the required level of performance, and because these results are affected by (un-avoidable) uncertainties in the source strengths, it may be prudent to assume that three one-atmosphere $\mathrm{BF}_{3}$ tubes would be needed, as had been previously indicated by Ely et al. (2009a). This would give a comfortable margin of error for the SAIC system. Higher pressure tubes should have better efficiency but introduce other significant problems such as requiring a higher operating voltage that is difficult to field.

The $\mathrm{BF}_{3}$ tubes require a substantially higher voltage $(2200 \mathrm{~V})$ to operate at 800 torr $\left(1.07 \times 10^{5} \mathrm{~Pa}\right)$ compared to ${ }^{3} \mathrm{He}$ tubes at about $1000 \mathrm{~V}$, which may be difficult to deploy to the field due to breakdown concerns in humid environments. Modifications to the SAIC electronics to operate these tubes would be necessary. Since $\mathrm{BF}_{3}$ is a hazardous gas, there are also concerns about deploying this gas in the field.

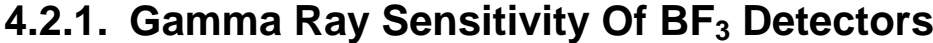

Data were taken with a large radiation source to determine the gamma sensitivity of the neutron detectors in the same manner describe above for the ${ }^{3} \mathrm{He}$ tubes, except spectra were collected for five-minute time periods using external electronics. The three-tube $\mathrm{BF}_{3}$ configuration has a similar response to the gammaray source as the ${ }^{3} \mathrm{He}$ tube. Shown in Figure 4.4 are the pulse height spectra for the various gamma ray exposure rates. As with the ${ }^{3} \mathrm{He}$, the count pileup is apparent even at the lowest dose rates compared to the background (source closed configuration). Although the electronics were not optimized for this test, it appears that the $\mathrm{BF}_{3}$ discriminator level could be set to eliminate the gamma noise up to about $100 \mathrm{mR} / \mathrm{hr}$ without significantly affecting the efficiency of the neutron detection.

In order to estimate the gamma-ray rejection factor, an estimate of the gamma flux is required. Since the $\mathrm{BF}_{3}$ tests were performed at the same time as the ${ }^{3} \mathrm{He}$ tests described above and in Appendix A, the same flux estimates apply, as summarized in Table A.2. With these values, and the analysis reported in Appendix $\mathrm{A}$, it can be determined that the $\mathrm{BF}_{3}$ tubes can discriminate neutrons from gamma rays up to the exposure rate of $40 \mathrm{mR} / \mathrm{hr}$. The gamma-ray rejection factor for the three-tube $\mathrm{BF}_{3}$ configuration is on the order of $6 \times 10^{-9}$. No measurements performed with the gamma ray and neutron source together and, thus, GARRn cannot be calculated. However, due to the significant gamma-ray rejection factor, it is expected that the GARRn for the $\mathrm{BF}_{3}$ tubes would meet the requirements. 


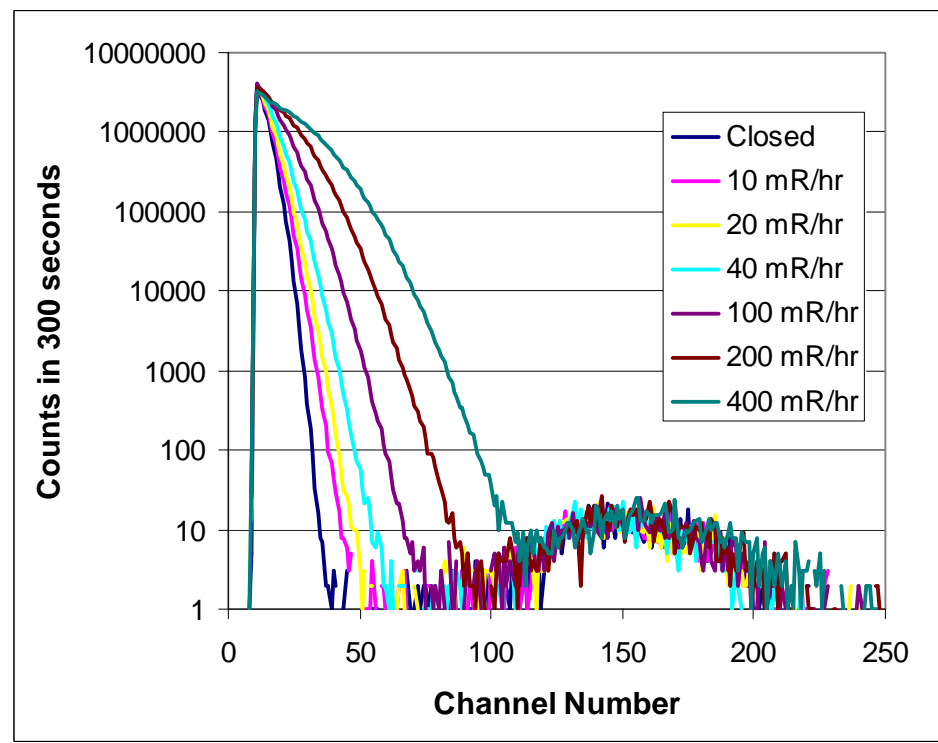

Figure 4.4. Pulse Height Spectra of The Three-Tube $\mathrm{BF}_{3}$ Configuration.

\subsection{Boron-Lined Neutron Detectors}

Two prototype boron-lined detection systems from GE Reuter Stokes were measured (Lintereur et al. 2009a; Kouzes et al. 2010b). Prototype II was a redesigned version of Prototype I with more boron-lined tubes and a modified moderator layout.

\subsubsection{Modeling Results For Boron-Lined Detectors}

In related work, a MCNPX model study of a generic 51-mm (2-inch) diameter boron-lined tube was performed. The result of the model, seen in Figure 4.5(a), shows the proportional counter spectrum produced by the alpha and ${ }^{7} \mathrm{Li}$ particles leaving the wall of the tube and depositing energy in the proportional gas. The alpha particles are emitted to both an excited state and the ground state, with the excited state alphas leading to the small shoulder at higher energy above the main alpha distribution. This model does not simulate the avalanche in the proportional tube, nor the electronic response, but even so the result matches the experimentally observed spectrum from the multi-tube GE Reuter Stokes Prototype I (Figure 4.5(b)) quite well.

\subsubsection{Absolute Neutron Efficiency Of Boron-Lined Detectors}

The data collected for the static measurements were used to determine the net count rate of the system and to estimate the absolute neutron detection efficiency. A lower level threshold was set in post analysis for the data acquired with the external electronics. This threshold was determined during the gamma insensitivity measurements to minimize the contribution from gamma rays, that is, to produce an acceptable GARRn value. The channel for the lower threshold was set one channel above the highest channel affected by a ${ }^{60} \mathrm{Co}$ exposure rate of $10 \mathrm{mR} / \mathrm{hr}$. This was channel 12 for Prototype I and channel 13 for Prototype II due to small changes in the electronics and the performance of the prototype. This threshold also produced acceptable GARRn values for higher exposure rates, up to $80 \mathrm{mR} / \mathrm{h}$ for Prototype II (slightly better than Prototype I). 


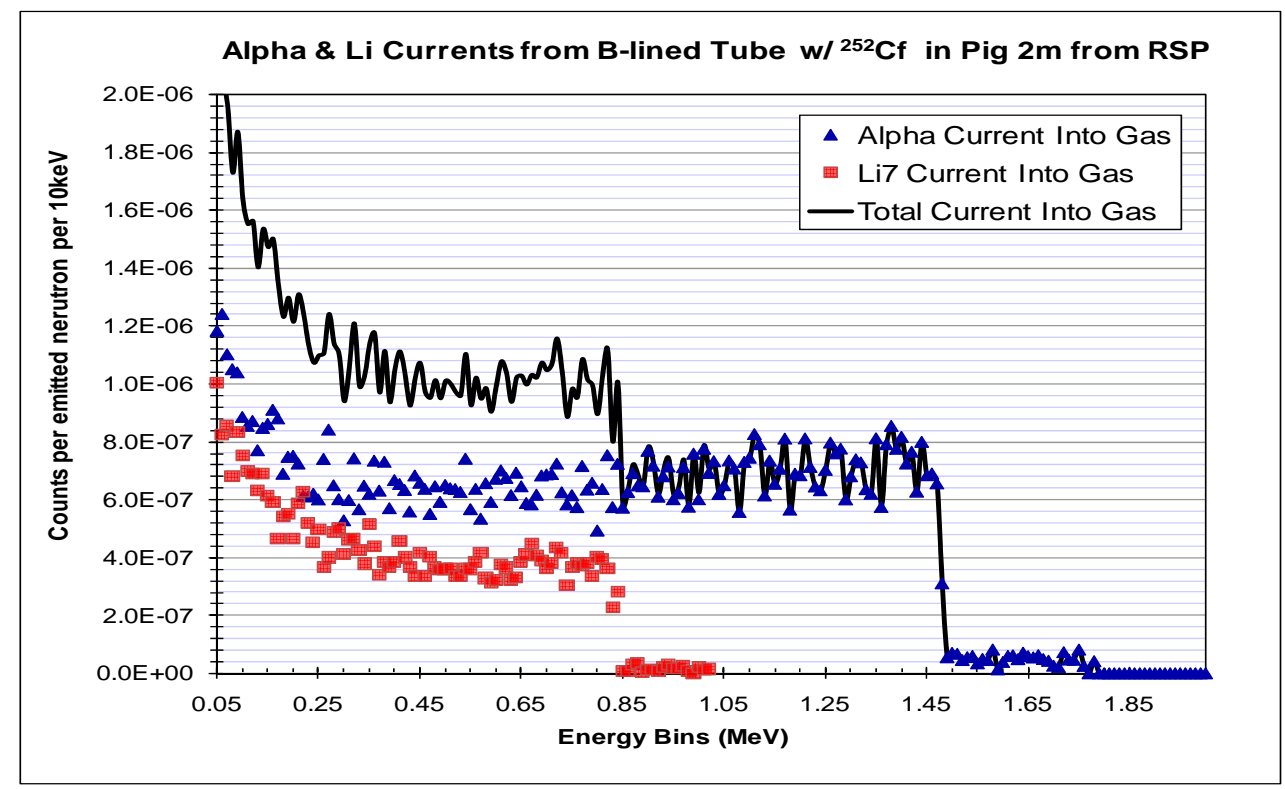

(a)

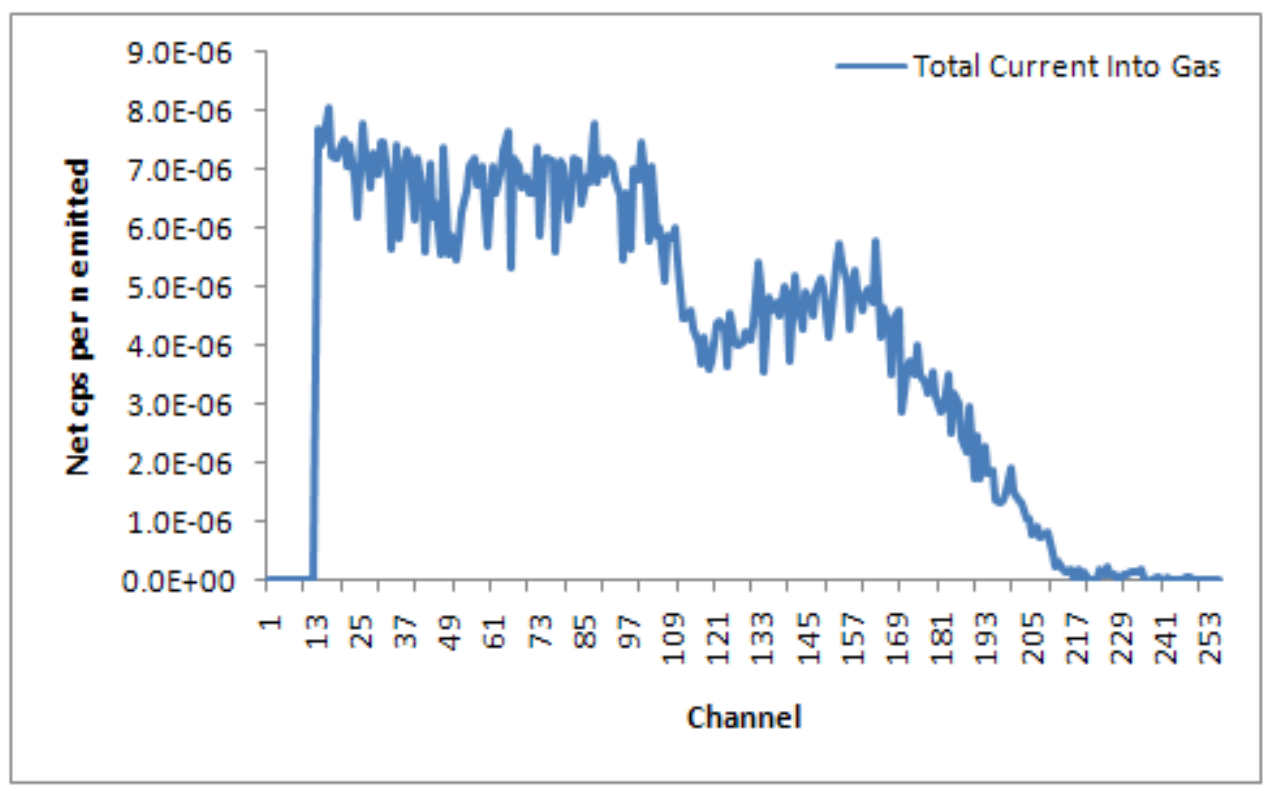

(b)

Figure 4.5: Modeling Result of Single Two-Inch Diameter Boron-Lined Tube Response to Neutrons (a), and Experimental Result for Response of Prototype I Detector System (b).

Data from the two segments of the detector (groups of tubes) were collected for 5 minutes for each measurement. The data above the lower level threshold were summed for the two segments of the detectors across all of the acquisition channels. The background was subtracted to determine the net count rate. The statistical uncertainty in the measurements is based on Poisson statistics and is less than the size of the plot symbols. The net count rate with the neutron source in its moderated form was measured with the detector system in the SAIC shroud with no additional moderator, as well as some other configurations. 
The absolute neutron efficiency of the system for the different configurations (including the different shaping times used) was determined. Figure 4.6 shows some of the absolute efficiency results from the GE Reuter Stokes Prototype I detector compared to a ${ }^{3} \mathrm{He}$-based detector. The efficiency of one ${ }^{3} \mathrm{He}$ tube with the external electronics is $2.95 \mathrm{cps} / \mathrm{ng}$. This figure shows that Prototype I did not reach the required efficiency. The absolute efficiency for Prototype I was 2.12(12) cps/ng (in the SAIC shroud with the outer door on), which is $85 \%$ of the required $2.5 \mathrm{cps} / \mathrm{ng}$. The uncertainty in the measurements is less than the size of the plot symbols and the total uncertainty is slightly more than the $5.7 \%$ that comes from the uncertainty in source strength.

The absolute efficiency for the GE Reuter Stokes Prototype II was 3.01(18) $\mathrm{cps} / \mathrm{ng}$ of ${ }^{252} \mathrm{Cf}$. This value is $24 \%$ above the specification value $(2.5 \mathrm{cps} / \mathrm{ng})$ for the neutron detection system and a $42 \%$ improvement over the Prototype I detector.

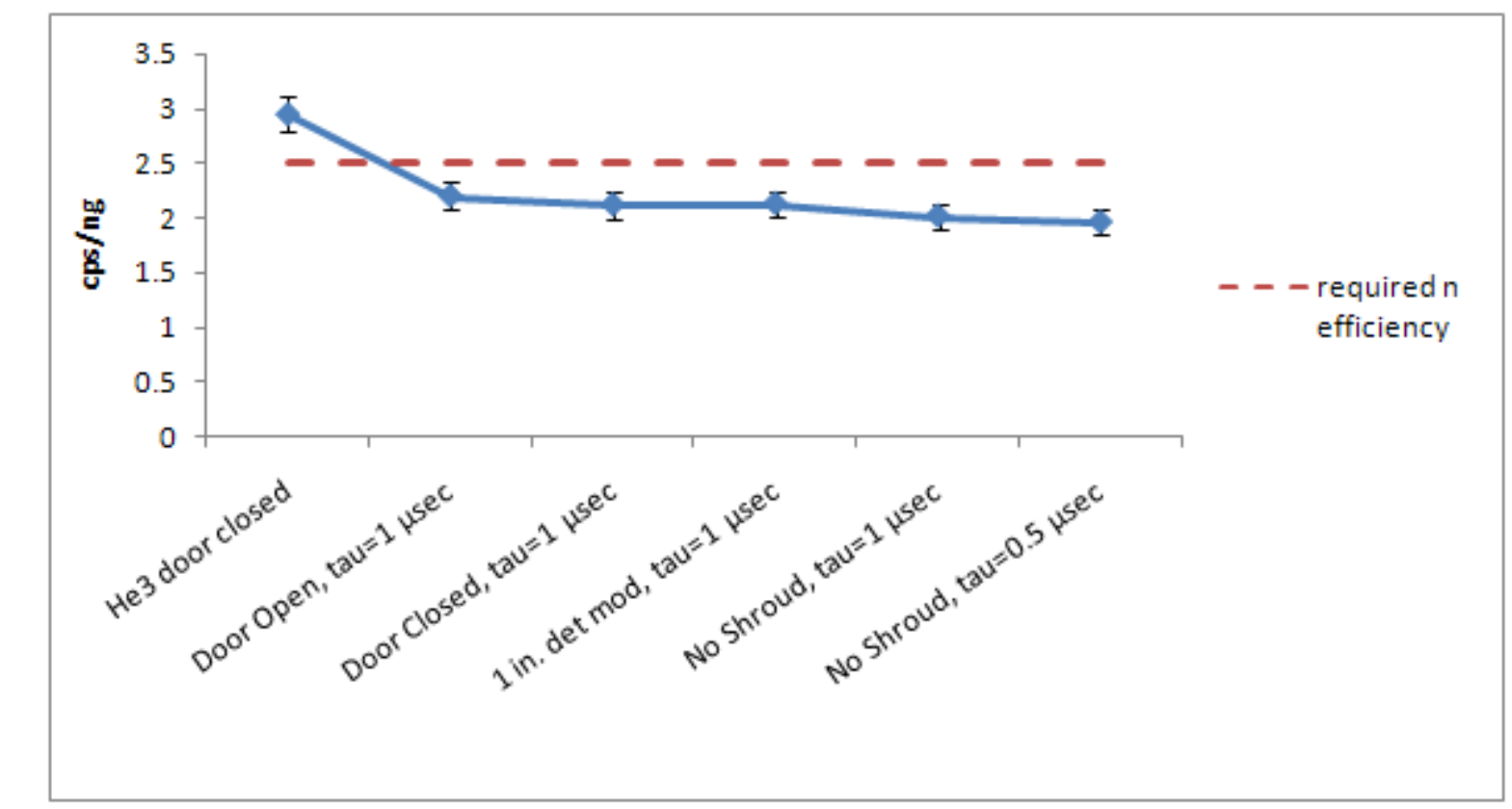

Figure 4.6: Neutron Efficiency Of Prototype I Detector System Under Different Test Scenarios Compared to One ${ }^{3}$ He Tube in The SAIC Moderating Box.

\subsubsection{Gamma Ray Sensitivity Of Boron-Lined Detectors}

The response of both prototypes of the boron-lined tubes to a high gamma exposure rate was evaluated with the ${ }^{60}$ Co source at the High Energy Calibration Laboratory in Building 318. The detector system in its moderating box was positioned at specific distances from the source to achieve the desired exposure rate at the detector surface. Data were collected over 5 minute time intervals for the four test configurations (background, ${ }^{60} \mathrm{Co},{ }^{252} \mathrm{Cf}$, and ${ }^{60} \mathrm{Co}$ with ${ }^{252} \mathrm{Cf}$ ). The background was subtracted from all of the test results with the neutron source to provide the net count rate at each position. The data were collected with the external electronics configured to have a shaping time of $0.5 \mu$ seconds to minimize the effect of the gamma rays on the signal. With these settings there was minimal detector response to the gamma source above channel 13 at exposure rates up to $100 \mathrm{mR} / \mathrm{hr}$. Figure 4.7 shows the response of the Prototype I boron-lined system to several gamma-ray exposure rates simultaneously with a neutron source. Figure 4.8 shows the response of the Prototype II system to the gamma-ray source. The boronlined detectors exhibit slightly less response to gamma rays than ${ }^{3} \mathrm{He}$ detectors over the exposure rates tested. 
The measurements were made indoors and the contribution to the scatter in the measured exposure rate increased with increasing distance from the source. The measured exposure rate was used to develop an estimate of the source strength and measurement uncertainty. The gamma factor for ${ }^{60} \mathrm{Co}$ used to determine the number of photons incident on the detector face for a given exposure rate was 13.2 $\mathrm{R} \cdot \mathrm{cm}^{2} / \mathrm{hr} \cdot \mathrm{mCi}$.

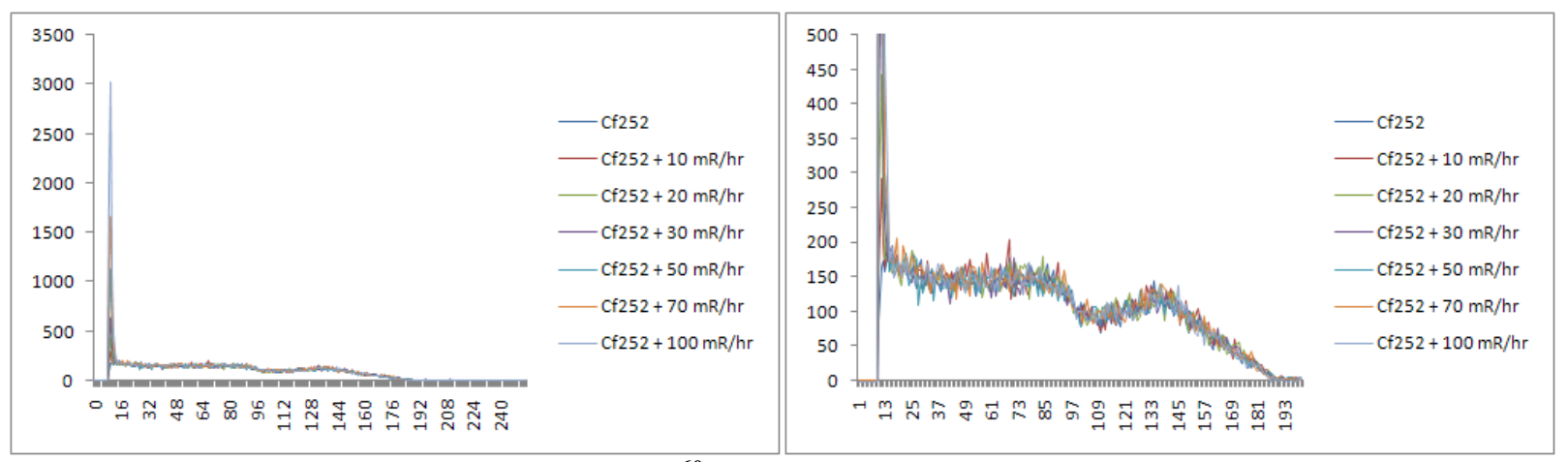

Figure 4.7: Boron Lined Tube Response to ${ }^{60}$ Co Gamma Rays (Left); Scaled to Show Detail (Right).

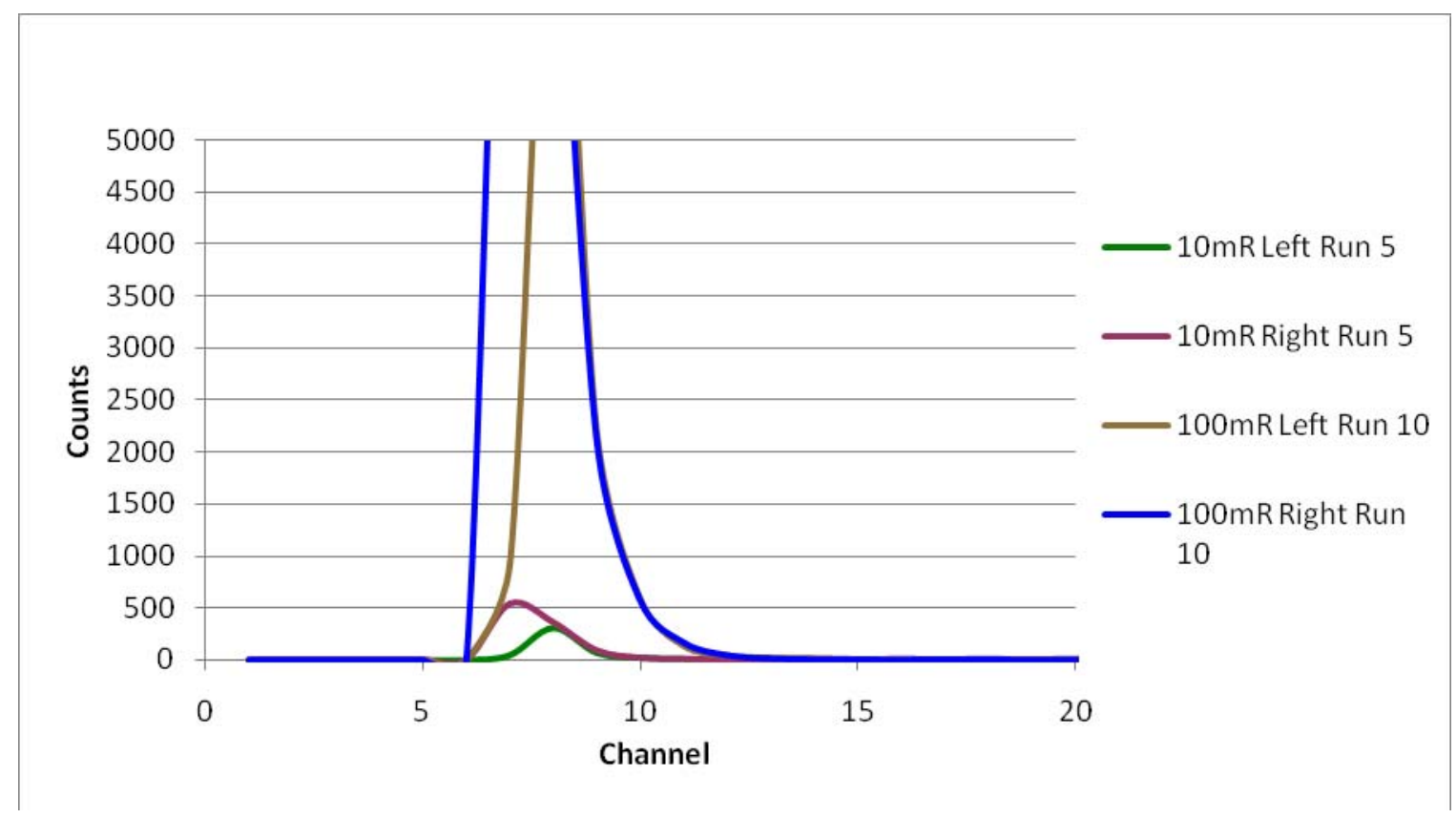

Figure 4.8. Pulse Height Spectra for GE Reuter-Stokes Prototype II from The Gamma Ray Source.

The GARRn values were calculated from the ratio of the absolute neutron efficiency with no gamma source present to the absolute neutron efficiency with the gamma source present. The absolute neutron efficiency was measured in the same position as the neutron efficiency measurements made with the gamma ray source present, thus eliminating any geometry effects on GARRn.

The results for Prototype II are summarized in Table 4.2, which shows that the measured GARRn values are well within the window specified $(0.9<$ GARRn $<1.1)$ for exposure rates up to $100 \mathrm{mR} / \mathrm{hr}$. The intrinsic efficiency for gamma rays detected as neutrons easily meets the required $10^{-6}$ at $10 \mathrm{mR} / \mathrm{hr}$. Both the intrinsic efficiency and GARRn have acceptable values for all exposure rates tested $(5 \mathrm{mR} / \mathrm{h}$ to 100 $\mathrm{mR} / \mathrm{h}$ ). Thus, with the lower limit threshold selected, gamma rays do not appear to have a significant 
effect on the boron-lined tubes, and their insensitivity to gamma rays is as good as, or better than, ${ }^{3} \mathrm{He}$ tubes. The gamma-ray discrimination performance of Prototype II was somewhat better than that of Prototype I.

Table 4.2: Prototype II Absolute Efficiency, GARRn And Intrinsic Efficiency Versus Exposure Rate.

\begin{tabular}{|c|c|c|c|}
\hline $\begin{array}{c}\text { Exposure Rate } \\
(\mathbf{m R} / \mathbf{h r})\end{array}$ & $\begin{array}{c}\text { Neutron Efficiency } \\
\mathbf{\epsilon}_{\mathbf{n}}(\mathbf{n} / \mathbf{s})\end{array}$ & $\begin{array}{c}\text { Intrinsic Gamma Ray Efficiency } \\
\mathbf{\epsilon}_{\text {int gngn }}\end{array}$ & $\begin{array}{c}\text { GARRn } \\
\mathbf{\epsilon}_{\mathbf{a b s}} \mathbf{~} \mathbf{n}\end{array}$ \\
\hline 0 & $1.4 \mathrm{E}-03$ & - \\
\hline 5 & $1.4 \mathrm{E}-03$ & - & $1.03(2)$ \\
\hline 10 & $1.4 \mathrm{E}-03$ & $2.0 \mathrm{E}-08$ & $1.01(2)$ \\
\hline 20 & $1.5 \mathrm{E}-03$ & $5.5 \mathrm{E}-09$ & $0.96(2)$ \\
\hline 30 & $1.5 \mathrm{E}-03$ & $3.4 \mathrm{E}-09$ & $0.95(2)$ \\
\hline 50 & $1.4 \mathrm{E}-03$ & $6.0 \mathrm{E}-09$ & $0.98(2)$ \\
\hline 70 & $1.3 \mathrm{E}-03$ & $3.3 \mathrm{E}-09$ & $1.04(2)$ \\
\hline 100 & $1.3 \mathrm{E}-03$ & $3.9 \mathrm{E}-09$ & $1.06(2)$ \\
\hline
\end{tabular}

\subsection{Lithium Loaded Glass Neutron Detectors}

Tests were performed for the absolute efficiency and gamma sensitivity of the lithium loaded glass fiber detectors (Ely et al. 2009b).

\subsubsection{Absolute Neutron Efficiency Of Lithium Loaded Glass Detectors}

The Nucsafe system utilizes three data processing filters (liberal, moderate and conservative) for the analysis of data from the lithium-loaded glass fiber detector. The filter used in the software is selected automatically based on the strength of the gamma-ray field. The liberal software filter results in the fewest rejected counts, but this filter is only used in very low gamma-ray background environments to prevent false neutron alarms. The moderate software filter is used in marginally higher gamma ray fields than the liberal filter; however, the moderate filter is not used in gamma ray fields above $\sim 1 \mathrm{mR} / \mathrm{h}$ to prevent false neutron alarms. The filter used when the system is in the presence of high gamma-ray exposure rates $(>1 \mathrm{mR} / \mathrm{h})$ is the conservative software filter. The conservative filter reduces false neutron alarms, but also results in the highest rejection rate for true neutron counts, which significantly decreases the neutron efficiency of the system. Note, for comparison purposes, the data were analyzed to provide the results from the three filters for each of the test configurations, however, the user output from the software did not include the results from the three filters under all the tested circumstances (i.e., in the presence of significant gamma ray exposures). The data from each filter were extracted in post analysis.

The data derived from the static tests were the average count rate over the five-minute acquisition time. The background measurements were subtracted from the neutron measurements to provide the net count rate. The net count rate from the static tests was used to determine the neutron detection efficiency of the system. The absolute neutron detection efficiency of the Nucsafe detector was determined by dividing the net count rate obtained with each moderator configuration by the mass (in nanograms) of the ${ }^{252} \mathrm{Cf}$ source, as shown in Figure 4.9. The uncertainty shown in the figure is dominated by the $\sim 15 \%$ source activity uncertainty since the statistical uncertainty is very small.

The neutron efficiency that would be obtained with a unit with the same outer moderator box dimensions as the current SAIC moderator box was estimated by multiplying the efficiency results by 5.4. The scaling factor was selected assuming the moderation thickness used would be the same regardless of detector size. The total available surface area in the currently deployed system minus the area required for the moderation was divided by the surface area of the Nucsafe system. The resulting factor (5.4) is 
thus the increase in active area that can likely be accommodated in the SAIC system while still leaving room for electronics. This is a conservative estimate, since scaling of the detector size without the moderator would allow for a factor of $>10$ increase in size. It must be noted that the scaling factor considers only the surface area of the moderator box and does not consider any increase in neutron efficiency that could be achieved from increasing the active volume (i.e., adding more layers of fibers). The potential neutron efficiency of the system scaled by a factor of 5.4 with the moderate filter is $1.72 \pm$ $0.62 \mathrm{cps} / \mathrm{ng}$, which is below the required value of $2.5 \mathrm{cps} / \mathrm{ng}$ (though scaling by a factor of 10 would meet the requirement). However, this assumes that the efficiency will increase linearly. Due to these assumptions, scaled efficiencies with the other filters and moderator thicknesses were not considered. Larger detector systems need to be tested to verify any predicted increase in efficiency, which could be more than that estimated here.

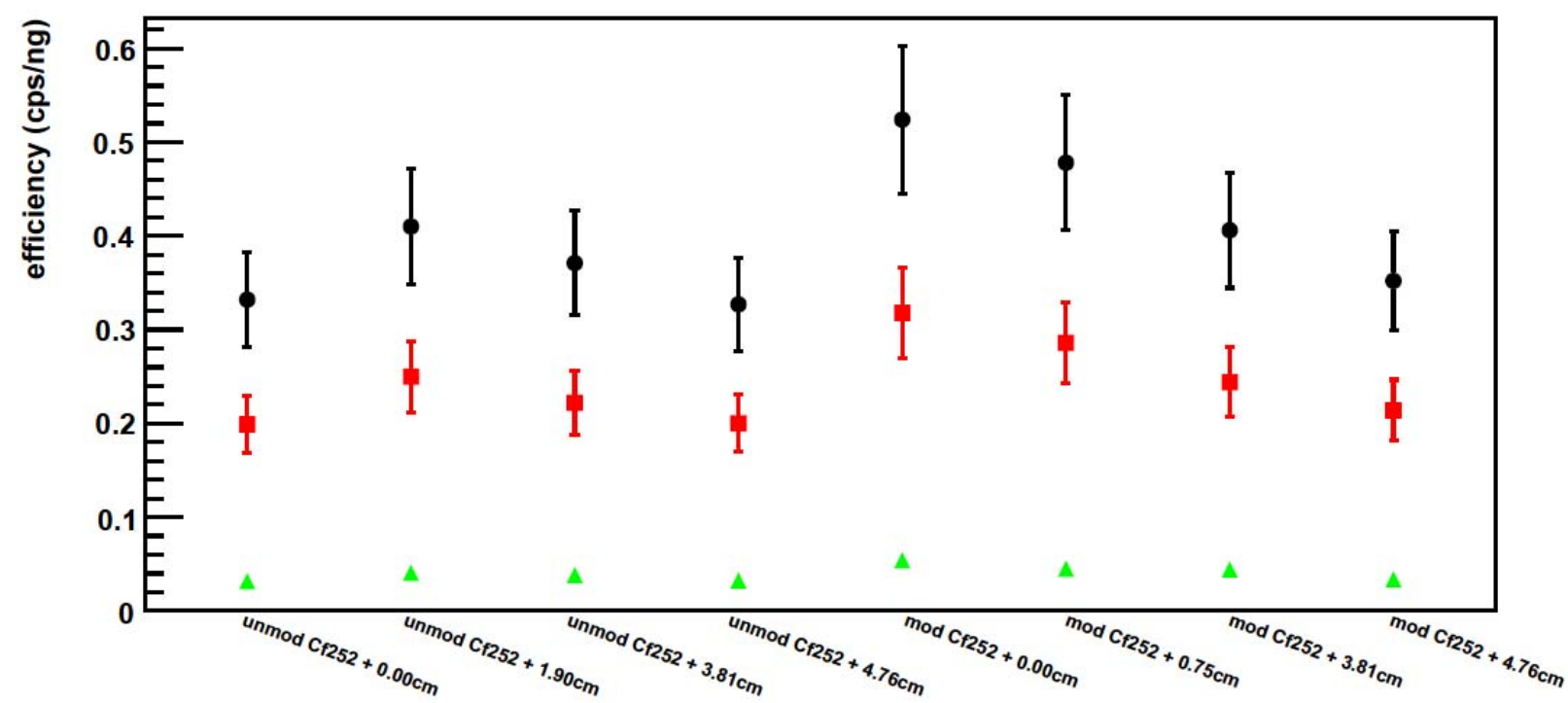

Figure 4.9: Approximate System Efficiency Calculated for The Nucsafe System Tested (Black=Liberal, Red=Moderate, Green=Conservative).

\subsubsection{Gamma Ray Sensitivity Of Lithium Loaded Glass Detectors}

The detector response to a high gamma-ray exposure rate was tested with the ${ }^{60} \mathrm{Co}$ source located in the Building 318 at PNNL. Data were collected over five minute intervals for the four configurations (background, ${ }^{60} \mathrm{Co},{ }^{60} \mathrm{Co}$ with ${ }^{252} \mathrm{Cf}$, and only ${ }^{252} \mathrm{Cf}$ ). The output from the three filters was analyzed for each of the measurement configurations. The difference between the three filters was very pronounced when the system was operated in the presence of gamma rays, as shown in Figure 4.10. The liberal filter resulted in an increase of over $240 \%$ between the neutron count rate recorded with no gamma-ray source present and the neutron count rate recorded in the presence of the lowest applied gamma-ray exposure rate $(10 \mathrm{mR} / \mathrm{h})$. The neutron count rate recorded with the liberal filter increased up to an exposure rate of $50 \mathrm{mR} / \mathrm{h}$ before decreasing, which indicates that the detector experiences some dead time at count rates higher than $\sim 110 \mathrm{cps}$. The neutron count rate recorded in the presence of a $10 \mathrm{mR} / \mathrm{h}$ gamma exposure rated with the moderate filter was 30\% higher than the neutron count rate recorded with no gamma source present. The conservative filter rejects the most gamma ray pulses; the highest increase in neutron count rate recorded with a gamma ray source present compared to without a gamma-ray source was $13 \%$. However, the conservative filter performs its gamma rejection at the cost of much lower neutron sensitivity and, thus, also rejects the most true neutron pulses of the three filters.

A value for efficiency and GARRn were obtained from the calculated photon flux on the detector and the absolute neutron efficiency. The absolute neutron detection efficiency value used for the determination of 
GARRn was the value associated with the geometry for each of the detector locations. The neutron source was located on the backside of the detector for the gamma ray measurements so the neutron efficiency used to calculate GARRn was calculated with the neutron source $2 \mathrm{~m}$ from the back of the detector. Thus, the effect of geometry on the value of GARRn cancelled. The highest absolute neutron efficiencies achieved with each of the filters and the absolute neutron efficiencies used to calculate GARRn are reported in Table 4.3. The GARRn values for the liberal and moderate filters are outside of the specified window $(0.9 \leq$ GARRn $\leq 1.10)$ for all of the applied gamma ray exposure rates. For the conservative filter, the GARRn value is within the specified range for all of the gamma ray exposure rates, but this comes at the expense of extremely low absolute neutron efficiency (best case is 0.05 , unscaled). Testing of a full size unit is required to verify these values for a larger system.

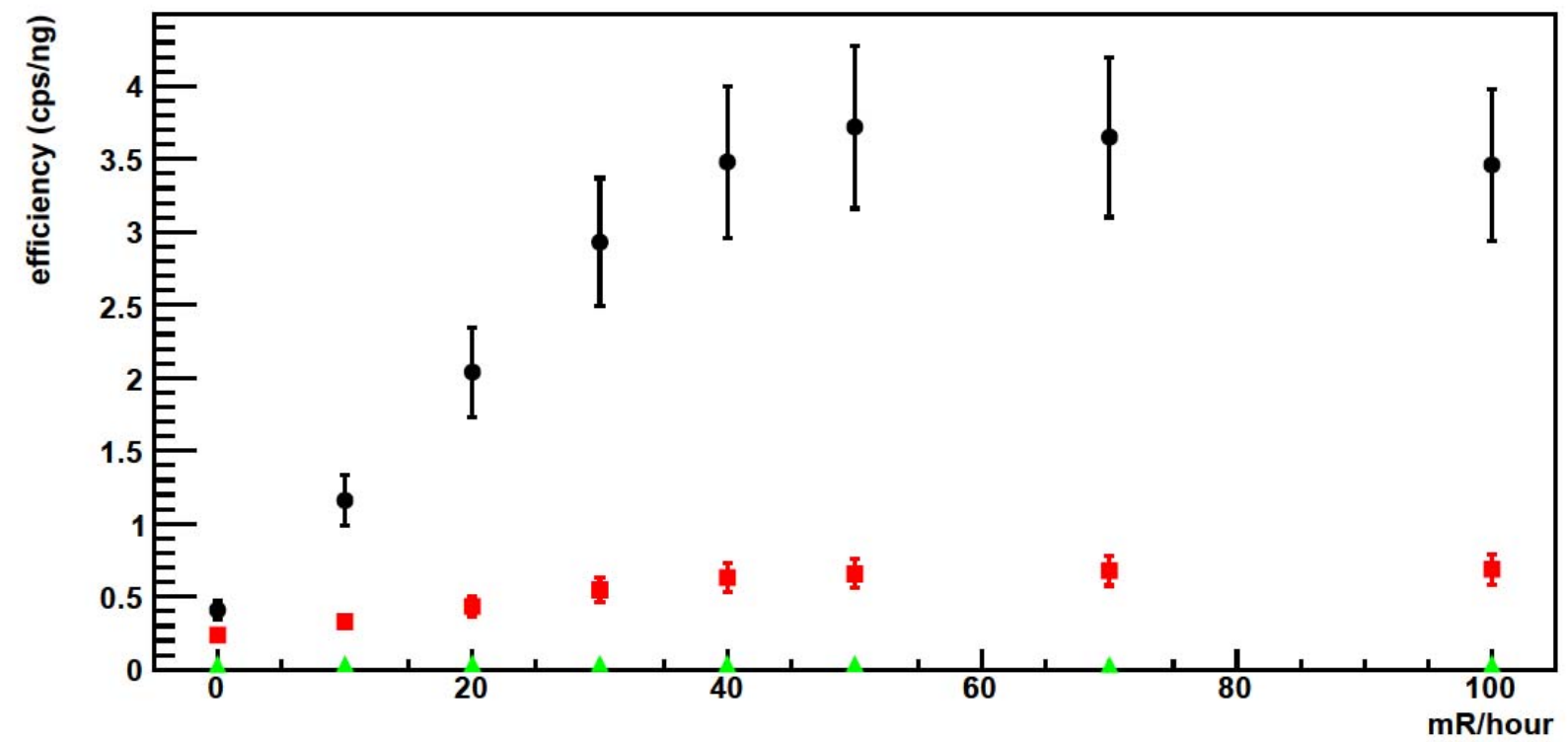

Figure 4.10: Efficiency of The Nucsafe Neutron Detector in Response to A Neutron Source and a Gamma Field (Black=Liberal, Red=Moderate, Green=Conservative).

The detector system tested had intrinsic gamma ray efficiencies $\left(\epsilon_{\text {int } \gamma \mathrm{n}}\right)$ on the order of $10^{-6}$ with the moderate filter for all of the exposure rates tested. The intrinsic gamma ray efficiency with the conservative filter was on the order of $10^{-8}$ for all of the exposure rates. The required intrinsic gamma-ray efficiency is $10^{-6}$. However, the intrinsic gamma-ray efficiencies for a given detection technology are dependent on the detector size, and therefore would potentially be different for a detector size (larger) that would meet the absolute efficiency requirements. Although promising, the intrinsic gamma-ray efficiency would need to be quantified for a larger detector.

Table 4.3: Absolute Efficiency, Intrinsic Gamma Ray Efficiency and GARRn at $10 \mathrm{mR} / \mathrm{h}$.

\begin{tabular}{|c|c|c|c|}
\hline Filter & $\begin{array}{c}\text { Absolute Efficiency } \\
\text { (best case) } \\
\mathbf{\epsilon}_{\text {abs n }}\end{array}$ & $\begin{array}{c}\text { Intrinsic Gamma } \\
\text { Ray Efficiency } \\
\mathbf{\epsilon}_{\text {int } \boldsymbol{~} \mathbf{n}}\end{array}$ & $\begin{array}{c}\text { GARRn } \\
\mathbf{\epsilon}_{\mathbf{a b s} \gamma \mathbf{n}} / \mathbf{\epsilon}_{\mathbf{a b s} \mathbf{n}}\end{array}$ \\
\hline Conservative & 0.05 & $1.49 \mathrm{E}-8$ & $1.07(6)$ \\
\hline Moderate & 0.32 & $4.63 \mathrm{E}-7$ & $1.31(3)$ \\
\hline Liberal & 0.52 & $3.94 \mathrm{E}-6$ & $2.70(4)$ \\
\hline
\end{tabular}

NucSafe is in the process of developing a full-scale system of a size appropriate for an SAIC system and is working on improving the gamma-ray rejection of the fibers and is expected to have another system ready for testing in the spring or summer of 2010. 


\subsection{Coated Plastic Fiber Neutron Detectors}

Two, coated plastic fiber systems from IAT were tested, a small system (Lintereur et al. 2009b), and a full-scale system designed to fit within the SAIC footprint (Kouzes 2010b).

\subsubsection{Absolute Neutron Efficiency Of Coated Plastic Fiber Detectors}

Measurements of the absolute neutron detection efficiency for the small and large IAT systems were performed with the IAT system software provided by the vendor, with the data from the large system summarized in Table 4.4. Backgrounds were acquired and subsequently subtracted from each test configuration to provide the net count rate. The uncertainty in the absolute values obtained was dominated by the uncertainty in the neutron source strengths. For the full-scale 4-paddle system, it was noted that Detector 1 had a somewhat higher background count rate, but the net rate was consistent with the other detectors and was included in the analysis of the static data. Measurements were also made with added polyethylene on the back of the detector unit, showing that there was a $12 \%$ increase in neutron detection efficiency with $38 \mathrm{~mm}$ of polyethylene added on the back of the detector, which acts as a reflector for neutrons. This indicates that the detector had an inadequate amount of reflector in its standard configuration.

The efficiency measurements were made at both the front and the back of the detector assembly with the moderated source at $2 \mathrm{~m}$ and perpendicular from the vertical and horizontal exterior of the housing. The net efficiency of the large system was found to be $2.0 \pm 0.1 \mathrm{cps} / \mathrm{ng}$ of ${ }^{252} \mathrm{Cf}$ for both the front and back of the detector, as expected given the symmetry of the moderator around the detectors paddles. This value falls short of the specified value of $2.5 \mathrm{cps} / \mathrm{ng}$. Based on the previous measurements of the smaller IAT system, it was anticipated that this full-scale system would meet the requirement. The vendor stated that they had manufactured the new paddles with an engineered process rather than the previous hand process. In the conversion to the engineered process, they had inadvertently reduced the ${ }^{6} \mathrm{Li}$ doping in the $\mathrm{ZnS}$.

At IAT, they revised their production of the detector paddles, and one new paddle was tested. One each of the new and old paddles was placed in a small moderator box for testing. Measurements showed that the new "enhanced" paddle did not perform significantly better in this small moderator configuration than the old paddle. For example, the count rates from each paddle for a neutron source at $2 \mathrm{~m}$ and the default threshold (zero) were 0.77 and $0.74 \mathrm{cps} / \mathrm{ng}$ for the new and old versions, respectively.

Table 4.4. Neutron Data from Full-Scale IAT Detector.

\begin{tabular}{|lcc|}
\hline \multicolumn{1}{|c}{ Configuration } & $\begin{array}{c}\text { Gross Sum of 4 } \\
\text { Detectors (cps) }\end{array}$ & Net cps/ng \\
\hline Efficiency: & & \\
Background & 3.37 & - \\
Source at 2 m from detector front & 80.22 & 1.98 \\
Source at 2 m from detector back & 81.26 & 2.01 \\
\hline 1.5" Polyethylene Reflector Added: & & \\
Background & 3.13 & - \\
Source at 2 m from detector front & 90.15 & 2.24 \\
Source at 2 m from detector back & 54.79 & 1.33 \\
\hline
\end{tabular}

The small system was upgraded in early 2010 , with a moderator geometry that will be incorporated into future full-scale systems, was tested for absolute efficiency (Kouzes 2010b). With the threshold chosen to have sufficient gamma ray rejection, the absolute efficiency of the sum of the system was found to be $0.84 \mathrm{cps} / \mathrm{ng}$. This efficiency can be compared to the previous test of the earlier small system (Lintereur et al. $2009 \mathrm{~b}$ ) of $0.50 \mathrm{cps} / \mathrm{ng}$. Thus, the improved design of this upgraded detector gave a $68 \%$ improvement in absolute efficiency. The caveat on this result is that the earlier measurements were performed outside 
while these new measurement were performed inside the PNNL 318 facility. Nonetheless, this performance enhancement is significant and if a full-scale system is built with this improved design, its performance should be substantially improved over the current full-scale system design.

At IAT, work continues on improving the detector system and process to manufacture paddles, and is expected to produce a proto-type that will meet the requirements in the spring of 2010.

\subsubsection{Gamma Ray Sensitivity Of Coated Plastic Fiber Detectors}

The sensitivity to gamma rays was tested with a ${ }^{60} \mathrm{Co}$ source flooding the entire detector active area with a high-exposure-rate gamma field. During some of the tests a ${ }^{252} \mathrm{Cf}$ neutron source was also used to test the neutron efficiency in the presence of gamma rays. Data were collected over five-minute intervals for four test configuration (background, ${ }^{60} \mathrm{Co}$ source, ${ }^{60} \mathrm{Co}$ plus ${ }^{252} \mathrm{Cf}$, and only ${ }^{252} \mathrm{Cf}$ ). Each of the four internal paddles of the full-scale system provided separate data. These data would normally be combined to obtain a composite count rate. However, one of the paddles (Detector 1) produced significantly more counts than the other three. Hence, the data from Detector 1 were not included in the analysis. Instead, the sum of the counts from the other three paddles was scaled to what would be expected if all four paddles were working similarly.

Figure 4.11 shows pulse height spectra obtained when only a neutron source was present, and Figure 4.12 shows pulse height spectra obtained when a neutron source was present and the gamma exposure rate was $10 \mathrm{mR} / \mathrm{hr}$. The different behavior of Detector 1 can be seen.

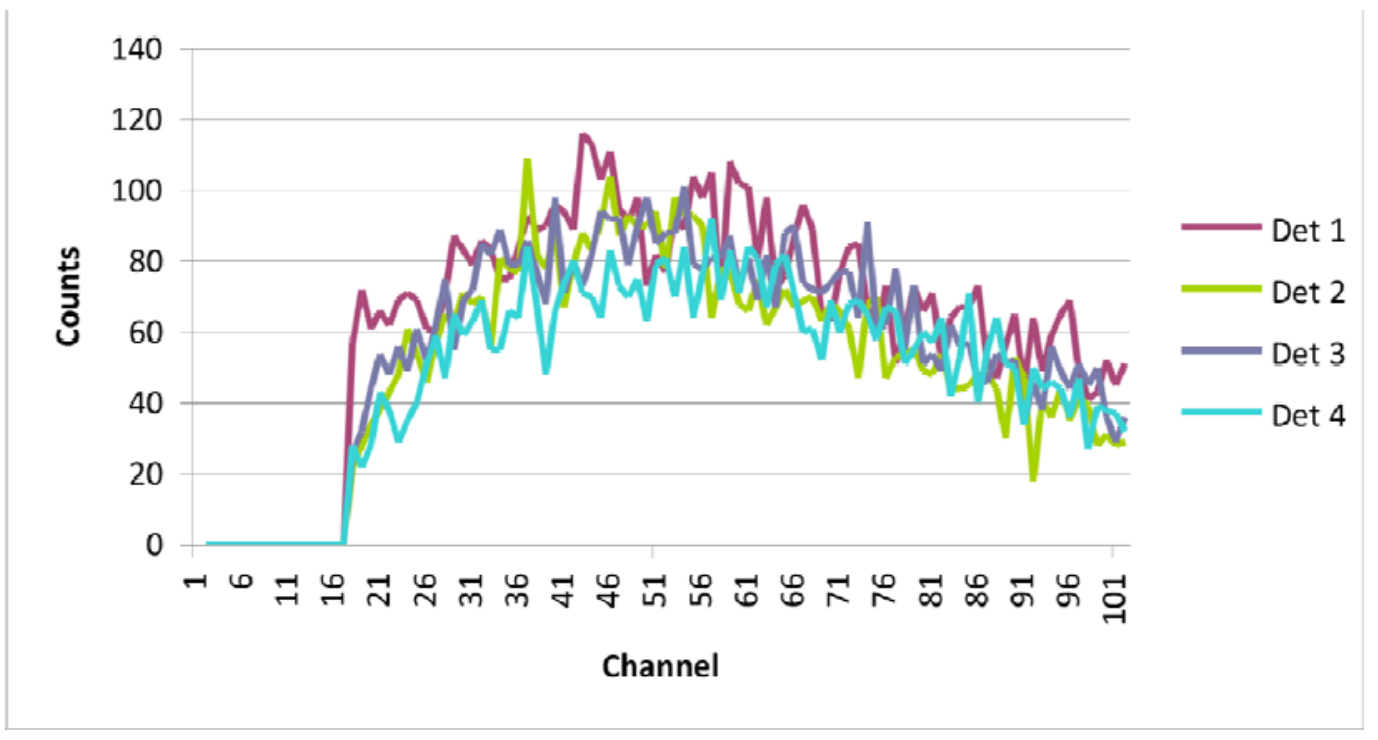

Figure 4.11. Pulse Height Spectra of The Four Detectors With Only The Neutron Source.

Values for the efficiencies and GARRn were determined from the calculated photon flux and the neutron efficiency. The neutron efficiency used to calculate GARRn for each gamma exposure was the absolute efficiency associated with each particular measurement. Thus, any geometrical effects cancel in the calculation. Table 4.5 shows the results for the full-scale IAT detector with a threshold at channel 43.

For a threshold of zero, the IAT detector tested has intrinsic gamma ray efficiencies $\left(\epsilon_{\text {int }} \gamma \mathrm{n}\right)$ on the order of $10^{-7}$ for ${ }^{60} \mathrm{Co}$ exposure rates up to $10 \mathrm{mR} / \mathrm{hr}$ and, thus, meets the required value of $10^{-6}$ for an exposure rate of $10 \mathrm{mR} / \mathrm{hr}$. For a threshold at channel 43 , the detector has $\epsilon_{\text {int } \gamma \mathrm{n}}$ on the order of $10^{-8}$ for ${ }^{60}$ Co exposure rates up to $20 \mathrm{mR} / \mathrm{hr}$. 
The GARRn value for ${ }^{60} \mathrm{Co}$ at $10 \mathrm{mR} / \mathrm{hr}$ was 1.0 with a threshold at channel 43 , within the desired window $(0.9 \leq$ GARRn $\leq 1.1)$, and provided the threshold used in the neutron efficiency analysis described in Section 4.5.1. The GARRn values for exposure rates above $10 \mathrm{mR} / \mathrm{hr}$ are outside the window, indicating that there is a loss of neutron efficiency and/or an increase in count rate from gamma rays when the detector is exposed to even larger gamma exposures.

The sensitivity to gamma rays of the upgraded small IAT system was tested. The measurements of this system with the gamma ray source indicated that a threshold at channel 40 would produce a GARRn value of 1.05 at an exposure rate of $10 \mathrm{mR} / \mathrm{h}$, which was then used to set the threshold for the neutron detection efficiency analysis described in Section 4.5.1.

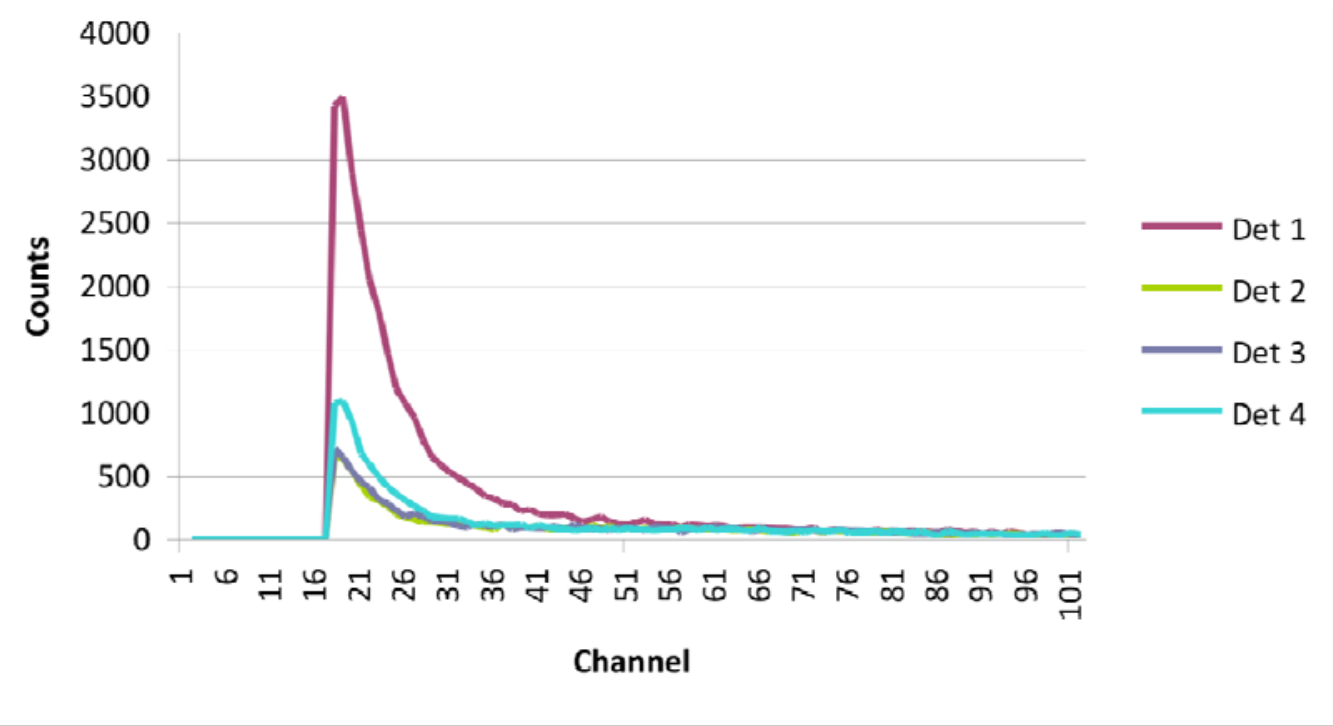

Figure 4.12. Pulse Height Spectra of The Four Detectors with Neutron and Gamma Ray Source.

Table 4.5. Absolute Efficiency, GARRn And Intrinsic Gamma Ray Rejection Factor For Different Gamma Exposure Rates For The Full-Scale Detector With Threshold Of 43.

\begin{tabular}{|c|c|c|c|}
\hline $\begin{array}{c}\text { Exposure Rate } \\
(\mathbf{m R} / \mathbf{h r})\end{array}$ & $\begin{array}{c}\text { Absolute Neutron Efficiency } \\
\mathbf{\epsilon}_{\mathbf{n}}\end{array}$ & $\begin{array}{c}\text { Intrinsic Gamma Ray Efficiency } \\
\boldsymbol{\epsilon}_{\text {int gn }}\end{array}$ & $\begin{array}{c}\text { GARRn } \\
\mathbf{\epsilon}_{\mathbf{a b s}} \mathbf{~} \mathbf{n}\end{array}$ \\
\hline 0 & 1.7 & - & 1 \\
\hline 5 & 2.0 & $4.2 \times 10_{\mathbf{n}}^{-9}$ & 1.10 \\
\hline 10 & 1.8 & $1.2 \times 10^{-8}$ & 1.03 \\
\hline 20 & 2.0 & $3.7 \times 10^{-8}$ & 1.14 \\
\hline 40 & 3.0 & $1.1 \times 10^{-7}$ & 1.67 \\
\hline 60 & 5.6 & $2.1 \times 10^{-7}$ & 3.12 \\
\hline 80 & 8.9 & $3.1 \times 10^{-7}$ & 5.02 \\
\hline 100 & 12.5 & - & 7.06 \\
\hline
\end{tabular}




\section{Conclusions}

Four different commercially available detectors have been tested as possible alternative neutron detection technologies for use in RPM systems. These technologies are:

1) Boron trifluoride-filled proportional counters,

2) Boron-lined proportional counters,

3) Lithium-loaded glass fibers, and

4) Coated non-scintillating plastic fibers.

The purpose of this testing was to measure the efficiency and gamma sensitivity of the various neutron detection system to determine which of these technologies could meet the specified neutron detector requirements. For this testing, the requirements were meeting the neutron detection, gamma-ray rejection, and GARRn specifications detailed in Section 2, with a detector module no larger than the current SAIC neutron detector module. The measurements made as part of this testing included the response of each system to moderated neutrons and to a high gamma-ray exposure rate. The outcome was the identification of technologies currently meeting the requirements for alternatives to ${ }^{3} \mathrm{He}$-based systems and the progress toward meeting them for the other technologies.

Table 5.1 summarizes the results of testing the various neutron-detection technologies. All systems can meet the intrinsic gamma-ray efficiency requirement and the resulting GARRn requirement with an appropriate threshold for the configurations tested. However, with this threshold, only the $\mathrm{BF}_{3}$ and boronlined alternatives as tested can also meet the absolute neutron detection requirement. The vendors for the lithium-loaded glass and coated-fiber detectors are working to improve the performance of their detectors to simultaneously meet all of these requirements. Increasing neutron detection efficiency can sometimes increase the gamma-ray detection capability, and therefore additional testing with gamma-ray exposures will be necessary with an upgraded system.

Table 5.1. Summary of Performance of Neutron Detection Technologies.

\begin{tabular}{|c|c|c|c|c|}
\hline Technology & $\begin{array}{c}\text { Exposure Rate } \\
(\mathrm{mR} / \mathrm{hr})\end{array}$ & $\begin{array}{c}\text { Absolute Neutron } \\
\text { Efficiency } \\
\text { (cps/ng) }\end{array}$ & $\begin{array}{c}\text { Intrinsic Gamma } \\
\text { Ray Efficiency } \\
\epsilon_{\text {int gn }}\end{array}$ & $\begin{array}{l}\text { GARRn } \\
\epsilon_{a b s} \gamma \mathbf{n} / \epsilon_{n}\end{array}$ \\
\hline Requirement & 10 & 2.5 & $1 \times 10^{-6}$ & $0.95<$ GARRn $<1.1$ \\
\hline \multirow{2}{*}{${ }^{3}$ He: 1 Tube } & 0 & $3.0(2)$ & - & - \\
\hline & 10 & $2.2(1)^{*}$ & $8 \times 10^{-8}$ & 1.00 \\
\hline \multirow{2}{*}{$\mathrm{BF}_{3}: 3$ Tubes } & 0 & $3.7(2)$ & - & - \\
\hline & 10 & not measured & $6 \times 10^{-9}$ & - \\
\hline \multirow{2}{*}{ Boron-Lined } & 0 & $3.0(2)$ & - & - \\
\hline & 10 & $3.2(2)$ & $6 \times 10^{-9}$ & 1.01 \\
\hline \multirow{2}{*}{ Lithium-Glass } & 0 & $1.7(6)^{\#}$ & - & - \\
\hline & 10 & $0.3(1)^{\#}$ & $1 \times 10^{-8}$ & 1.07 \\
\hline \multirow[t]{2}{*}{ Coated-Fiber } & 0 & $2.0(1)$ & - & - \\
\hline & 10 & $1.8(1)$ & $1.2 \times 10^{-8}$ & 1.03 \\
\hline
\end{tabular}

* Measured in different geometry than used at zero exposure rate (at back of detector).

${ }^{\#}$ Scaled by a factor of 5.4 for comparison to other full-scale systems (see text). 
There appears to be at least one configuration of ${ }^{3} \mathrm{He}$ that would reduce the amount of ${ }^{3} \mathrm{He}$ consumption (by about 1/3) by increasing to a two-tube solution in the SAIC cargo module while decreasing the pressure in each tube to one atmosphere. This two-tube configuration was tested and shown to have the same capability as the single tube configuration at higher pressure. This configuration may not be relevant considering the current ${ }^{3} \mathrm{He}$ demand for RPMs, however, it may be useful for other types of neutron detectors.

Although this testing indicates that two of the technologies can meet the basic neutron detection requirements, additional considerations should be incorporated into a decision to select a technology for further development and integration into RPMs. The coated fibers appear to be a promising technology. The $\mathrm{BF}_{3}$ tubes are attractive from the neutron detection capability, but the gas is hazardous, and the tubes have a higher operating voltage. The latest boron-lined tube prototype system has good neutron detection efficiency; the tubes do not contain hazardous material and have reasonable operating voltages. However, due to the lower inherent efficiency, a more complex system is needed to meet the requirements, which may result in a more expensive solution. Both of the tube solutions are mature technologies that have been used for neutron detection applications in the past, and therefore pose little risk for integration into a field system.

The ${ }^{6} \mathrm{Li} / \mathrm{ZnS}(\mathrm{Ag})$-coated neutron plastic fibers show great promise and may ultimately be able to provide better neutron detection efficiency per unit volume compared to the proportional tubes. This could be important if the neutron detection requirements increase for a different RPM system or a different type of neutron detector. However, the coated fibers are a relatively new approach and may require additional development and testing. For example, the technology is temperature sensitive, and the vendor is developing a method for accounting for this effect, but it has not been implemented to date and will need adequate testing prior to field deployment. The scintillating glass fibers are currently the least attractive technology, but the vendor is investigating methodologies to increase the neutron detection capability, especially in the presence of gamma rays.

The testing has been specific to the SAIC RPM system and scaled to the TSA RPM system. It is expected that both the $\mathrm{BF}_{3}$ and boron-lined solutions would provide the current neutron detection capability of the TSA system in the current footprint, and the coated fibers when the upgraded prototypes become available. However, it is recommended that before further development and integration for the TSA system proceed, promising technologies be tested in the TSA form factor with the SLD program requirements to validate the scaling calculations.

If a technology is selected for further development for use in a RPM, additional work will be required to integrate the technology into a specific portal system. For some applications, the desire is to simply replace the current ${ }^{3} \mathrm{He}$-based neutron detection module with the new alternative without modifying the portal electronics. This may require additional electronics to be developed in the alternative neutron detection module, to be able to provide a similar output as a ${ }^{3} \mathrm{He}$ based module. Once the alternative module has been developed and integrated into the RPM, additional testing, including environmental and other robustness testing, will be required before implementing into fielded systems to ensure the system meets the entire suite of requirements. 


\section{References}

ANSI. 2004. American National Standard for Evaluation and Performance of Radiation Detection Portal Monitors for Use in Homeland Security. Technical Report. ANSI 42.35, American Nuclear Standards Institute, Washington, D.C.

Ely, JR, RT Kouzes, AT Lintereur, JE Schweppe, ER Siciliano, ML Woodring. 2009a. "BF 3 Neutron Detector Testing And Comparison To ${ }^{3} \mathrm{He}$," Technical Rpt. PNNL-18581, Pacific Northwest National Laboratory, Richland, WA.

Ely, JR, LE Erikson, RT Kouzes, AT Lintereur, ER Siciliano, 2009b. "Lithium Loaded Glass Fiber Neutron Detector Tests,” Technical Rpt. PNNL-18988, Pacific Northwest National Laboratory, Richland, WA.

Kouzes RT, J Ely, and E Siciliano. 2007. "Neutron Alarm Algorithms for Deployed RPMs.” Technical Rpt. PNNL-17101, Pacific Northwest National Laboratory, Richland, WA.

Kouzes, RT, JH Ely, PE Keller, RJ McConn, and ER Siciliano. 2008. "Passive Neutron Detection for Interdiction of Nuclear Material at Borders." Nuclear Instruments and Methods in Physics Research Section A: Accelerators, Spectrometers, Detectors and Associated Equipment 584(2-3): 383-400.

Kouzes, RT. 2009a. “The ${ }^{3}$ He Supply Problem,” Technical Rpt. PNNL-18388, Pacific Northwest National Laboratory, Richland, WA.

Kouzes, RT, M Wright, RK Crawford, JL Robertson (ORNL), 2009b. “The ${ }^{3}$ He Supply Problem And Possible Alternative Technology," Technical Rpt. PNNL-18550, Pacific Northwest National Laboratory, Richland, WA.

Kouzes RT, JR Ely, AT Lintereur, DL Stephens. 2009c. "Neutron Detector Gamma Insensitivity Criteria." Technical Rpt. PNNL-18903, Pacific Northwest National Laboratory, Richland, WA.

Kouzes, RT, ER Siciliano, 2009d. "Modeling ${ }^{3} \mathrm{He}$ Neutron Detector Modification And BF 3 Comparison," Technical Rpt. PNNL-18648, Pacific Northwest National Laboratory, Richland, WA.

Kouzes, RT, ER Siciliano, 2009e. “3He Neutron Detector Pressure And Geometry Modification,” Technical Rpt. PNNL-18667, Pacific Northwest National Laboratory, Richland, WA.

Kouzes, RT, JR Ely, AT Lintereur, ER Siciliano, ML Woodring. 2009f. "BF 3 Neutron Detector Tests," Technical Rpt. PNNL-19050, Pacific Northwest National Laboratory, Richland, WA.

Kouzes, RT, JR Ely, AT Lintereur, ER Siciliano, DC Stromswold, ML Woodring. 2010a. “33e Neutron Detector Pressure Effect And Comparison To Models," Technical Rpt. PNNL-19110, Pacific Northwest National Laboratory, Richland, WA.

Kouzes, RT, LE Erikson, WJ Kernan. 2010b. "Full Scale Coated Fiber Neutron Detector Measurements," Technical Rpt. PNNL-19264, Pacific Northwest National Laboratory, Richland, WA.

Lintereur, AT, RT Kouzes, JR Ely, LE Erikson, ER Siciliano 2009a. "Boron Lined Neutron Detector Measurements," Technical Rpt. PNNL-18938, Pacific Northwest National Laboratory, Richland, WA.

Lintereur, AT, JR Ely, RT Kouzes, LE Erikson, DC Stromswold. 2009b. "Coated Fiber Neutron Detector Test,” Technical Rpt. PNNL-18919, Pacific Northwest National Laboratory, Richland, WA.

Stromswold D, J Ely, R Kouzes, J Schweppe. 2003. Specifications for Radiation Portal Monitor Systems Revision 6.7. Technical Rpt. PNNL-14716, Pacific Northwest National Laboratory, Richland, WA. 
Van Ginhoven, RM, RT Kouzes, DL Stephens, 2009. “Alternative Neutron Detector Technologies for Homeland Security,” Technical Rpt. PNNL-18471, Pacific Northwest National Laboratory, Richland, WA. 


\section{APPENDIX A}

\section{Additional Description of ${ }^{3} \mathrm{He}$ Filled Proportional Tube Neutron Detector Tests}

Four sets of measurements were performed to address various problems that arose in the measurement campaign. For the first set of tests, measurements were made for one and two $304 \mathrm{kPa}(3 \mathrm{~atm})$ tubes and for the $101 \mathrm{kPa}(1 \mathrm{~atm})$ tube without problems; but, the $203 \mathrm{kPa}(2 \mathrm{~atm})$ and $253 \mathrm{kPa}(2.5 \mathrm{~atm})$ tubes both exhibited the problem of producing excessively large pulses at the recommended operating voltage. The $203 \mathrm{kPa}(2 \mathrm{~atm})$ tube seemed to work correctly for $\sim 10$ minutes before demonstrating this behavior, which was interpreted as voltage breakdown. The $253 \mathrm{kPa}(2.5 \mathrm{~atm})$ tube yielded large pulses immediately. Usable data were obtained at $850 \mathrm{~V}$, even though this was below the plateau region as defined by the manufacturer. Further investigation of this problem showed the tubes functioned correctly in the laboratory. Connector breakdown may have been the cause of the problem.

The subsequent measurements were performed with the same tubes with external electronics to bias the tubes and record the data. The external electronics were used to increase the range of available voltages and to prevent the SAIC electronics from affecting the results. The second set of measurements was performed without difficulty. However, the value obtained for the single $304 \mathrm{kPa}$ ( $3 \mathrm{~atm}$ ) tube did not provide the expected trend, so a third set of measurements was performed. The third set gave the expected trend, but raised the question of whether one of the two $304 \mathrm{kPa}(3 \mathrm{~atm})$ tubes was at fault, so the fourth set of measurements was made to see if the results from the two $304 \mathrm{kPa}$ ( $3 \mathrm{~atm}$ ) tubes were consistent.

Figure 6.1 shows the pulse height spectra observed out of three of the various pressure tubes. All the tubes provide similar performance in terms of fractional width and separation of the neutron response from noise.

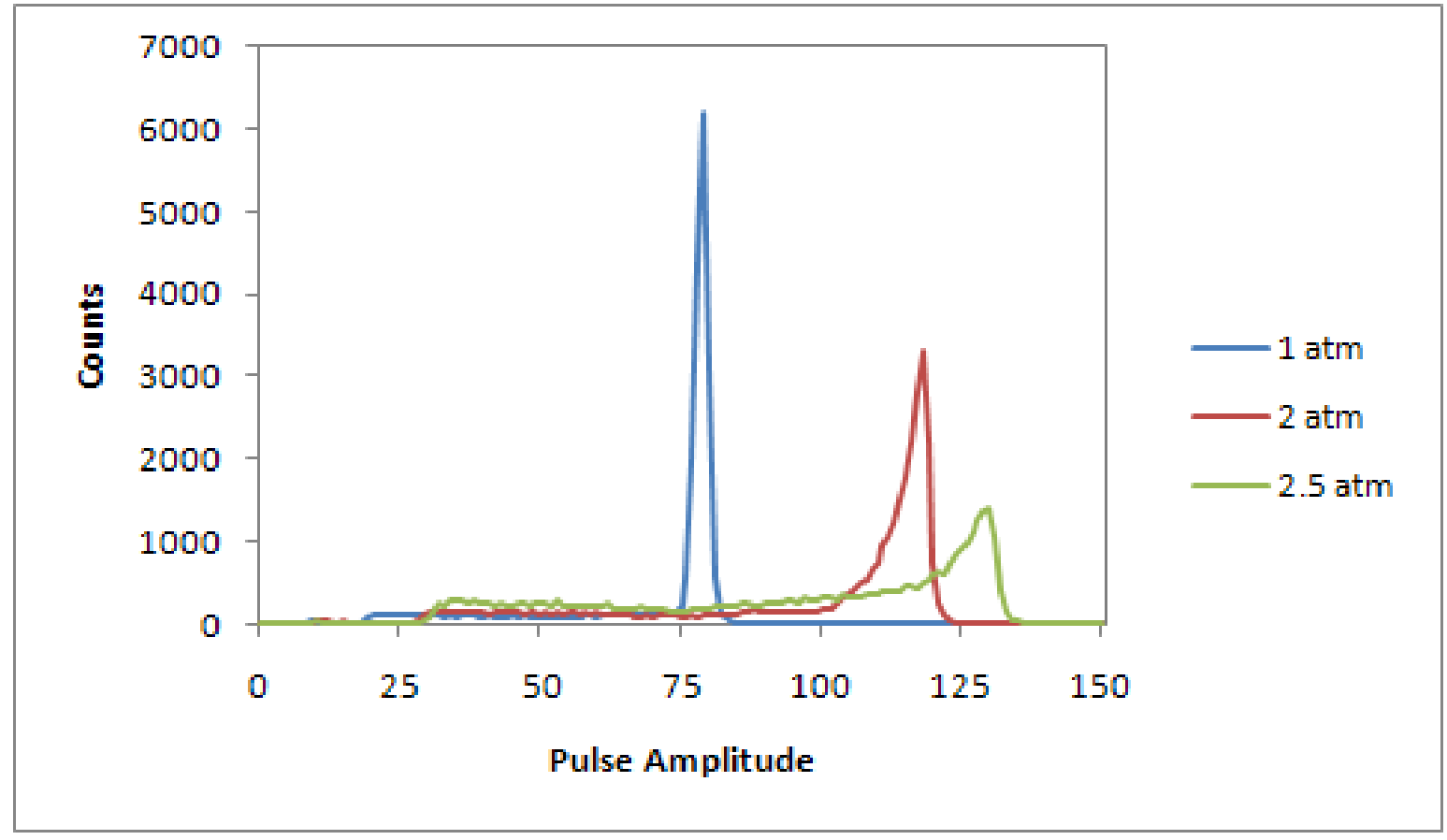

Figure A.1. Illustrative Pulse Height Spectra for Different Pressure ${ }^{3}$ He Tubes. 


\section{A.1 Absolute Neutron Efficiency Of ${ }^{3} \mathrm{He}$ Detectors}

For the data collected on the ${ }^{3} \mathrm{He}$ tube with the SAIC electronics during the first test, the count rates were collected in 30-s intervals for a total of five minutes and averaged to give counts per second (cps) for background and the two source configurations. The net count rates recorded at different tube pressures are listed (with uncertainties in parentheses) in Table A.1. The values shown for counts per second per nanogram are the renormalized results. The value for the $203 \mathrm{kPa}(2 \mathrm{~atm})$ tube appears low; this tube showed apparent breakdown problems during testing and the data taken before and after the breakdown were not consistent.

Table A.1. Measurement Results for Four Campaigns.

\begin{tabular}{|c|c|c|c|c|}
\hline \multicolumn{5}{|c|}{$1^{\text {st }}$ Campaign } \\
\hline One Tube & Tube ID* & Partial Pressure kPa (atm) & cps & cps/ng \\
\hline & 325177 & $101(1.0)$ & $68.0(5)$ & 1.71 \\
\hline & 325186 & $203(2.0)$ & $67.2(5)$ & 1.69 \\
\hline & 325183 & $253(2.5)$ & $93.2(6)$ & 2.35 \\
\hline & 102439 & $304(3.0)$ & $106.6(6)$ & 2.68 \\
\hline \multicolumn{5}{|l|}{ Two Tubes } \\
\hline Left & unknown & $304(3.0)$ & $76.6(5)$ & 2.05 \\
\hline Right & unknown & $304(3.0)$ & $75.2(5)$ & 2.02 \\
\hline Total & & $304(3.0)$ & $151.8(7)$ & 4.07 \\
\hline \multicolumn{5}{|c|}{$2^{\text {nd }}$ Campaign } \\
\hline \multirow[t]{5}{*}{ One Tube } & Tube ID ${ }^{1}$ & Partial Pressure kPa (atm) & cps & cps/ng \\
\hline & 325177 & $101(1.0)$ & $74.4(5)$ & 1.9 \\
\hline & 325186 & $203(2.0)$ & $103.6(6)$ & 2.6 \\
\hline & 325183 & $253(2.5)$ & $117.3(6)$ & 2.9 \\
\hline & 102439 & $304(3.0)$ & $114.0(6)$ & 2.9 \\
\hline \multicolumn{5}{|l|}{ Two Tubes } \\
\hline Left & 325180 & $101(1.0)$ & $62.4(5)$ & 1.6 \\
\hline Right & 325177 & $101(1.0)$ & $60.2(5)$ & 1.5 \\
\hline Total & & $101(1.0)$ & $122.5(7)$ & 3.1 \\
\hline \multicolumn{5}{|c|}{$3^{\text {rd }}$ Campaign } \\
\hline \multirow[t]{5}{*}{ One Tube } & Tube ID & Partial Pressure kPa (atm) & cps & cps/ng \\
\hline & 325177 & $101(1.0)$ & $79.1(5)$ & 2.0 \\
\hline & 325186 & $203(2.0)$ & $104.8(6)$ & 2.6 \\
\hline & 325183 & $253(2.5)$ & $113.3(6)$ & 2.9 \\
\hline & 102345 & $304(3.0)$ & $127.3(7)$ & 3.2 \\
\hline \multicolumn{5}{|c|}{$4^{\text {th }}$ Campaign } \\
\hline \multirow[t]{6}{*}{ One Tube } & Tube ID & Partial Pressure kPa (atm) & cps & cps/ng \\
\hline & 325177 & $101(1.0)$ & $77.0(5)$ & 1.92 \\
\hline & 325186 & $203(2.0)$ & $105.2(6)$ & 2.63 \\
\hline & 325183 & $253(2.5)$ & $117.8(6)$ & 2.95 \\
\hline & 102439 & $304(3.0) \mathrm{A}$ & $113.0(6)$ & 2.83 \\
\hline & 102345 & $304(3.0) \mathrm{B}$ & $123.0(7)$ & 3.08 \\
\hline
\end{tabular}


For the second campaign, results were obtained for four one-tube tests and one two-tube test. Table A.1 lists the net count rates recorded at different tube pressures and the resulting counts per second per nanogram of ${ }^{252} \mathrm{Cf}$. The (unexpected) drop in the $304 \mathrm{kPa}(3 \mathrm{~atm})$ tube efficiency is seen. This apparently anomalous result for the $304 \mathrm{kPa}$ ( $3 \mathrm{~atm}$ ) tube led to the third set of measurements to verify if one of the tubes had a problem that produced this inconsistency.

The results from the third test are shown in Table A.1. The values found are consistent with the previous measurements with the exception of the result from the $304 \mathrm{kPa}$ tube, which for this test continued the expected upward trend. This result initiated the fourth test campaign in order to determine if one of the two $304 \mathrm{kPa}(3 \mathrm{~atm})$ tubes that were originally in the system tested was less efficient.

The main purpose of the fourth test was to test the consistency between the two $304 \mathrm{kPa}(3 \mathrm{~atm})$ tubes. The results of the measurements are given in Table A.1. It can be seen that the absolute efficiencies for tubes A and B differ significantly, which explains the differences seen in earlier measurements. The measurements for all pressures agree across the four sets of measurements when the two different " 3 atm" tubes are understood to be different in efficiency. The most likely explanation is that tube A currently has a lower pressure than the $304 \mathrm{kPa}(3 \mathrm{~atm})$ stated by the vendor, and is actually about $243 \mathrm{kPa}(2.4 \mathrm{~atm})$, though there may be some other explanation.

Figure 4.2 summarizes the results from the tests of ${ }^{3} \mathrm{He}$ detection efficiency versus pressure. This graph is based on data taken with external electronics, and does not include the filtering impact of the SAIC electronics. It shows a consistent increase in efficiency with pressure except for the anomaly at $3 \mathrm{~atm}$, which arises from the apparent loss of efficiency in one of the two tubes tested.

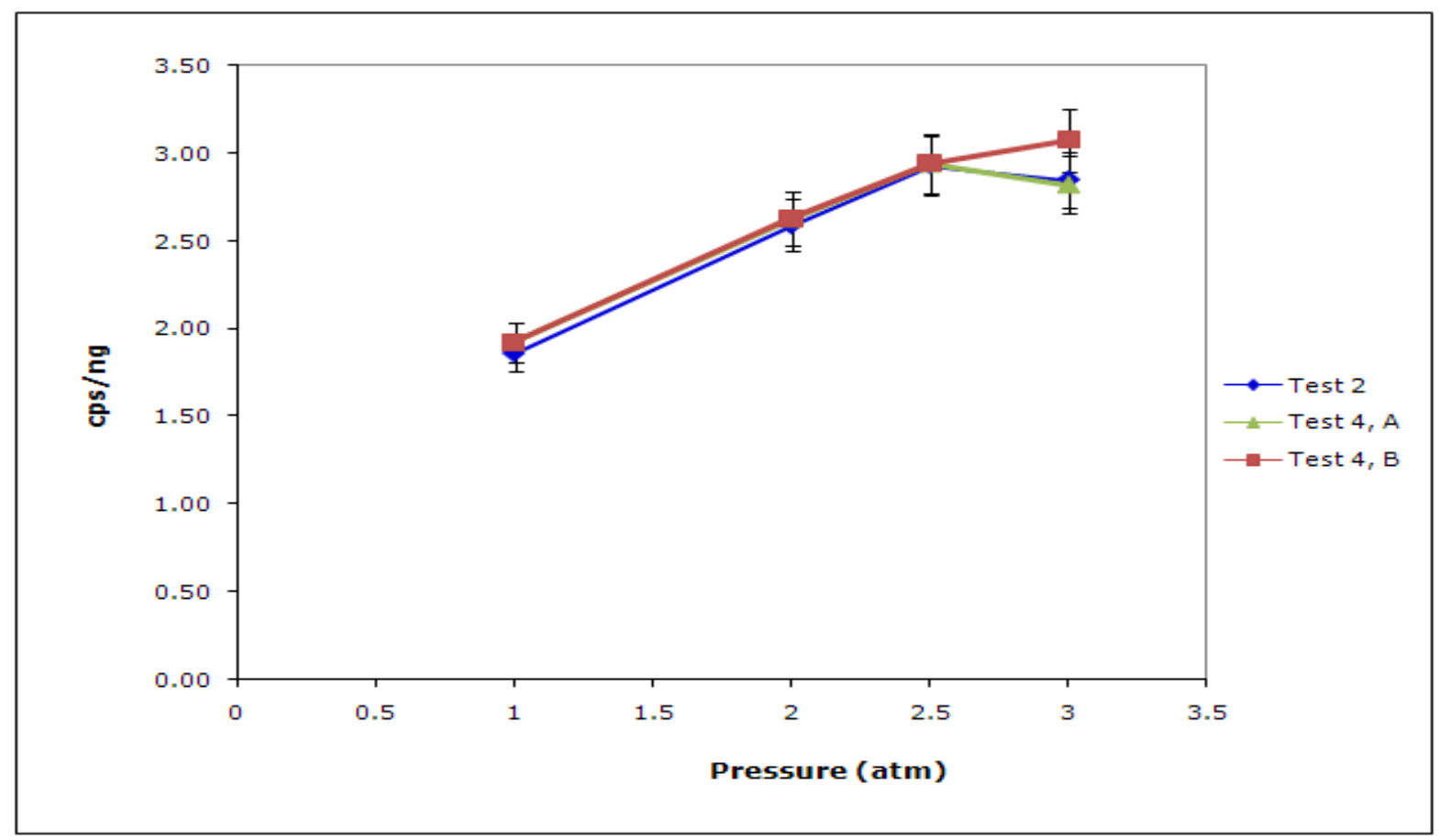

Figure A.2. Efficiency Versus Partial Pressure from Second and Fourth Campaign. 

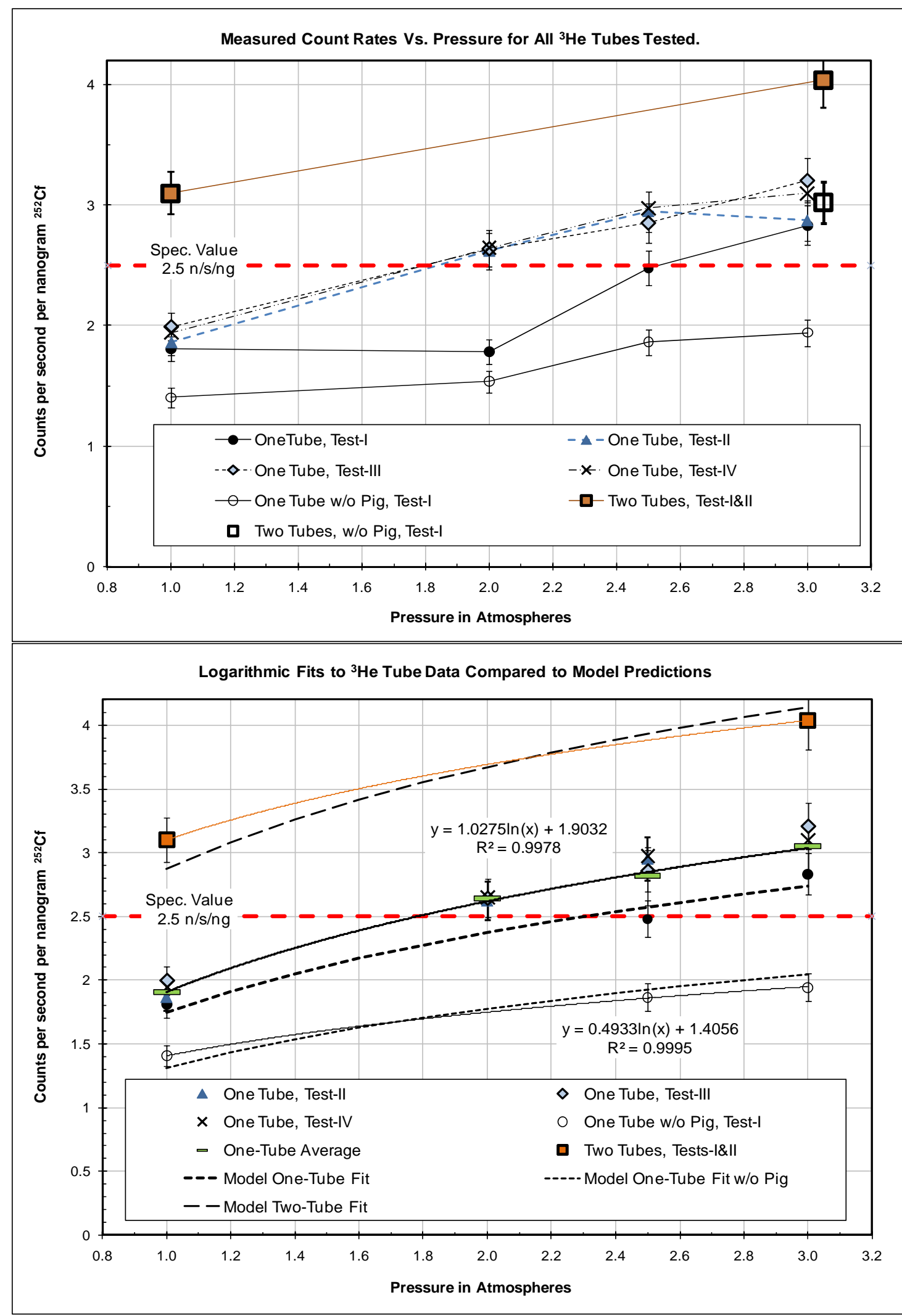

Figure A.3. Data from All Tests (Top). Data Compared to Model as Function of Pressure (Bottom). 
Because the experimental data described in this report were taken over four different test campaigns, and because some of those data were considered less reliable than others; the first step in comparing those results to the model predictions was to collect all the measured values into one chart. These are shown in the top chart of Figure A.3, where, except for the 3(A) value from Table A.1, the total set of measured values listed in this report is displayed. The only un-moderated source values were recorded during Test I. Note that there were only three measurements made for a two-tube configuration, two values at 304 $\mathrm{kPa}$ in first test campaign and one value at $101 \mathrm{kPa}$ in the second campaign. Apparent from Figure A.3 are the obviously anomalous values reported for the $203 \mathrm{kPa}(2 \mathrm{~atm})$ tube used in Test I and the $304 \mathrm{kPa}$ ( $3 \mathrm{~atm}$ ) tube in Test II. Repeat measurements were made to correct the problems seen in Test I, and the efficiency problem with one $304 \mathrm{kPa}^{3} \mathrm{He}$ tube was identified. Without further justification, those data are omitted from the following comparison.

The bottom graph of Figure A.3 is used to compare the set of measured data to the results from model calculations. For the moderated, one-tube results considered, this comparison was made by first determining the average values from that set of data, and then fitting the predicted logarithmic function to determine how well that particular functional form described the data. That fit is shown as a thick solid line, and can be seen to describe the data extremely well. As for the absolute values, however, the thick dashed line shows the logarithmic function plotted with the model fitted parameters (after multiplying by $2300 \mathrm{n} / \mathrm{s} / \mathrm{ng}$ ), and is seen to lie below the averaged measured values by $7 \%$ to $9 \%$.

A similar analysis was performed for the three unmoderated source, one-tube values taken during Test I. The thin solid line shows the logarithmic parameters obtained by fitting those data, and the thin dashedline is the curve produced with the corresponding unmoderated source ("w/o Pig") model fitted values. Opposite to the "w/Pig" comparisons, the model prediction for this case tends to have a slightly different shape and overestimate the observed cps/ng values.

A fit to the two moderated source ("w/Pig"), two-tube values was not made because one ("3A") of the two $304 \mathrm{kPa}(3 \mathrm{~atm})$ tubes used for the two-tube measurements in Test I was found (in Test-IV) to be performing slightly under its partner ("3B"), and thus suspected of having a pressure slightly less than the vendor's designation. Nevertheless, those two two-tube data are compared to the corresponding model predicted logarithmic curve shown as the long-dashed lines in Figure 4.3. Note from that comparison, the two-tube $101 \mathrm{kPa}(1 \mathrm{~atm})$ measurement is slightly above the predicted value, a behavior consistent with the one-tube comparison. On the other hand, the two-tube $304 \mathrm{kPa}(3 \mathrm{~atm})$ value is slightly below the model prediction, which is inconsistent the one-tube behavior, and again a result of tube " $3 \mathrm{~A}$ " being less than "3B" in its individual performance.

The above differences are reasonable for MCNP ab initio calculations, since such models typically overestimate performance rather than underestimate it because there is no loss of efficiency from electronics included in the model calculations. Because the difference in the modeled and experimental results is probably not due solely to the uncertainty in the source strength, as shown by measurements with several sources, further investigation is needed to explain the small difference between the model predictions and the measured values.

Considering the variations in the measured values about their average, the differences between the model predictions and average measured values are not large enough to change the main conclusion derived from the model results. Thus, it is advised that no reduction in ${ }^{3} \mathrm{He}$ pressure be considered for the SAIC system. However, the option of two $101 \mathrm{kPa}(1 \mathrm{~atm})$ tubes to replace one $304 \mathrm{kPa}(3 \mathrm{~atm})$ tube is validated. 


\section{A.2 Gamma Ray Sensitivity Of ${ }^{3} \mathrm{He}$ Detectors}

Data were taken with a large radiation source to determine the gamma sensitivity of the neutron detectors. Spectra were collected for five-minute time periods at several exposure rates with the SAIC electronics. The spectra for the ${ }^{3} \mathrm{He}$ detector with the SAIC electronics are shown in Figure A.4. The SAIC multichannel analyzer cuts out the low pulse height noise at a fixed value. The gamma source starts to provide a pileup signal in the low pulse height region even at the lowest exposure tested $(10 \mathrm{mR} / \mathrm{hr})$ and exceeds the lower level hardware discriminator. There are additional software discriminators and filters used for noise reduction, but, at the hardware level, it appears that the system could be set to discriminate the gamma noise up to a level of about $100 \mathrm{mR} / \mathrm{hr}$. Before that exposure rate, the neutron peak (just above channel 100) starts to decrease in amplitude and becomes broader.

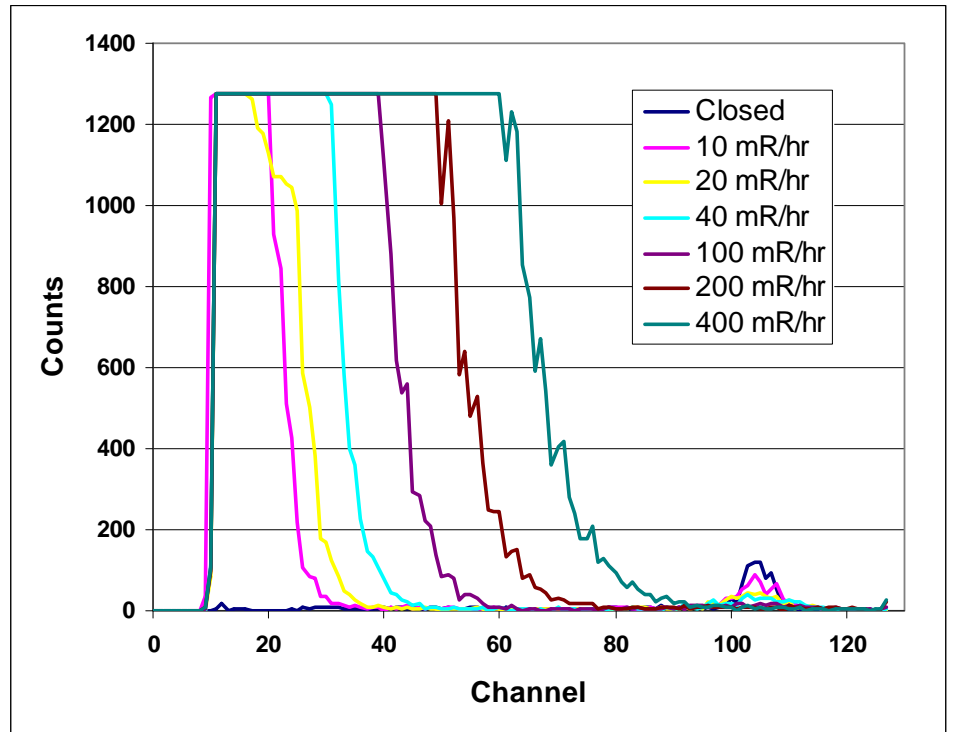

Figure A.4. Spectra Of ${ }^{3}$ He Tube Response In The Presence Of A Large Gamma Source.

In order to estimate the gamma ray rejection factor, an estimate of the gamma flux is required. The approach used to estimate the photon flux was from exposure rate measurements. The source provided was 24.2 $\mathrm{Ci}$ for the test day. With an average value of 2.1265 gamma rays emitted per disintegration along with the distance to the RSP face, an estimate of the number of photons incident on a tube was made. A simple calculation, ignoring the effects of air, provides one estimate of the incident photon rate on the area of the tube by scaling the emitted flux by distance squared (column 2 of Table A.2). A more accurate estimate can be made with the measured exposure rate. An 'effective' activity of the ${ }^{192}$ Ir source was found from the exposure rate, distance, and the exposure rate constant for ${ }^{192}$ Ir. This effective activity takes into account some of the air effects and can then be used to estimate the photon flux. Column 3 of Table A.2 gives the effective source strength and column 4 gives the derived incident photon rate on the area of the tube.

From the table, both methods provide similar values for incident photon rate on a single tube. With these values, and the analysis above indicating that the tubes can still discriminate neutrons up to the exposure rate of $40 \mathrm{mR} / \mathrm{hr}$, it is possible to estimate the gamma ray rejection factor. The gamma-ray rejection factor for the single ${ }^{3} \mathrm{He}$ tube is on the order of $2 \times 10^{-8}$. This rejection factor of $\sim 10^{-8}$ or better makes the proportional tube technology far superior to any scintillator-based technology. 
Table A.2. Estimated Photon Flux on a Single Tube

\begin{tabular}{|c|c|c|c|}
\hline $\begin{array}{c}\text { Exposure Rate } \\
(\mathbf{m R} / \mathbf{h r})\end{array}$ & $\begin{array}{c}\text { Estimated } \\
\text { Photons on Tube } \\
\text { From Source } \\
\text { Strength }\end{array}$ & $\begin{array}{c}\text { 'Effective' } \\
\text { Source Activity } \\
\mathbf{( C i )}\end{array}$ & $\begin{array}{c}\text { Estimated Photons } \\
\text { on Tube using } \\
\text { Effective Activity }\end{array}$ \\
\hline 10.5 & $1.5 \mathrm{E}+07$ & 21.9 & $1.3 \mathrm{E}+07$ \\
\hline 20 & $2.6 \mathrm{E}+07$ & 23.5 & $2.5 \mathrm{E}+07$ \\
\hline 43.5 & $5.1 \mathrm{E}+07$ & 26.5 & $5.5 \mathrm{E}+07$ \\
\hline 100 & $1.1 \mathrm{E}+08$ & 27.1 & $1.3 \mathrm{E}+08$ \\
\hline 200 & $2.3 \mathrm{E}+08$ & 26.8 & $2.5 \mathrm{E}+08$ \\
\hline 400 & $4.6 \mathrm{E}+08$ & 27.1 & $5.1 \mathrm{E}+08$ \\
\hline
\end{tabular}




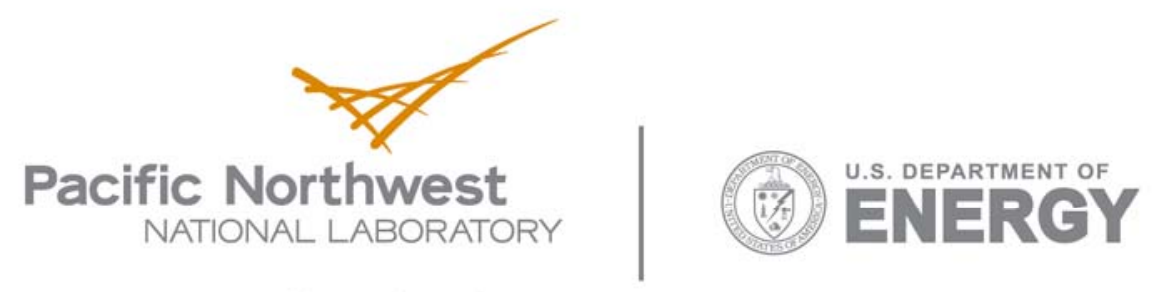

902 Battelle Boulevard

P.O. Box 999

Richland, WA 99352

1-888-375-PNNL (7665)

www.pnl.gov 